\title{
Vanadate Induces Necrotic Death in Neonatal Rat Cardiomyocytes Through Mitochondrial Membrane Depolarization
}

\author{
Sandra Sofia Soares, ${ }^{\dagger, \star}$ Fernando Henao, ${ }^{\S}$ Manuel Aureliano, ${ }^{\ddagger, \| l}$ and \\ Carlos Gutiérrez-Merino*, \\ Comparative Cardiovascular Physiopathology Group (GFCC), Faculty of Environmental and Marine Sciences, \\ Centre of Marine Sciences (CCMAR), and Department of Chemistry, Biochemistry and Pharmacy, Faculty of \\ Sciences and Technology, University of Algarve, Campus de Gambelas, 8005-139 Faro, Portugal, and Group of \\ Bioenergetics in Neurones and Myocytes, Department of Biochemistry and Molecular Biology, Faculty of \\ Sciences, University of Extremadura, Av. Elvas s/n, 06071 Badajoz, Spain
}

Received June 6, 2007

\begin{abstract}
Besides the well-known inotropic effects of vanadium in cardiac muscle, previous studies have shown that vanadate can stimulate cell growth or induce cell death. In this work, we studied the toxicity to neonatal rat ventricular myocytes (cardiomyocytes) of two vanadate solutions containing different oligovanadates distribution, decavanadate (containing decameric vanadate, $\mathrm{V}_{10}$ ) and metavanadate (containing monomeric vanadate and also di-, tetra-, and pentavanadate). Incubation for $24 \mathrm{~h}$ with decavanadate or metavanadate induced necrotic cell death of cardiomyocytes, without significant caspase- 3 activation. Only $10 \mu \mathrm{M}$ total vanadium of either decavanadate $\left(1 \mu \mathrm{M} \mathrm{V}_{10}\right)$ or metavanadate (10 $\mu \mathrm{M}$ total vanadium) was needed to produce $50 \%$ loss of cell viability after $24 \mathrm{~h}$ (assessed with MTT and propidium iodide assays). Atomic absorption spectroscopy showed that vanadium accumulation in cardiomyocytes after $24 \mathrm{~h}$ was the same when incubation was done with decavanadate or metavanadate. A decrease of $75 \%$ of the rate of mitochondrial superoxide anion generation, monitored with dihydroethidium, and a sustained rise of cytosolic calcium (monitored with Fura-2-loaded cardiomyocytes) was observed after $24 \mathrm{~h}$ of incubation of cardiomyocytes with decavanadate or metavanadate concentrations close to those inducing 50\% loss of cell viability produced. In addition, mitochondrial membrane depolarization within cardiomyocytes, monitored with tetramethylrhodamine ethyl esther or with 3,3',6,6'-tetrachloro-1,1',3,3'tetraethylbenzimidazolcarbocyanine iodide, were observed after only $6 \mathrm{~h}$ of incubation with decavanadate or metavanadate. The concentration needed for $50 \%$ mitochondrial depolarization was $6.5 \pm 1 \mu \mathrm{M}$ total vanadium for both decavanadate $\left(0.65 \mu \mathrm{M} \mathrm{V}_{10}\right)$ and metavanadate. In conclusion, mitochondrial membrane depolarization was an early event in decavanadate- and monovanadate-induced necrotic cell death of cardiomyocytes.
\end{abstract}

\section{Introduction}

Several studies have reported the ability of inorganic and organic vanadium compounds to modulate cardiovascular function and their potential usefulness as protection agents against ischemia/reperfusion injury in cardiac tissue (1-3). Reports on the biological effects of vanadate and other vanadium-containing compounds in heart cells are mainly related to their insulinmimetic features $(4,5)$ and to their ability to increase the contractile force of heart muscle, that is, their inotropic effect (6-8). However, several studies have shown vanadate effects varying from stimulation of cell growth to induction of cell death (9-14). Moreover, in most cases, the vanadate effect on cell proliferation was biphasic, being cytotoxic for cells over a concentration range of 50-100 $\mu \mathrm{M}(15)$. The major aims of these studies were to analyze vanadate-induced genes expression, oxidative burst, changes in cytosolic calcium, and cytosk-

\footnotetext{
* To whom correspondence should be addressed. (for C. G.-M.) Tel: +34 924 289419. Fax: +34 924 289419. E-mail: carlosgm@unex.es. (for S. S. S.) E-mail: sssoares@ualg.pt.

Comparative Cardiovascular Physiopathology Group (GFCC), Faculty of Environmental and Marine Sciences, University of Algarve.

Centre of Marine Sciences (CCMAR), University of Algarve.

$\S$ University of Extremadura.

"Department of Chemistry, Biochemistry and Pharmacy, Faculty of Sciences and Technology, University of Algarve.
}

eleton alterations without special attention to the effects of vanadium treatments on cell viability $(4,16-18)$. Thus, it is not clear whether these cellular effects are related to vanadate toxicity. Because of the potential toxic effects of vanadium compounds, their use as supplements in the diet of athletes is not recommended $(7,8)$. However, it should be noted that vanadium is present in many food products used in a normal human diet $(19,20)$, and once incorporated into tissue cells, vanadium is only very slowly eliminated from mammals, leading to progressive vanadium accumulation during the life span $(21,22)$.

The most widely investigated vanadium compound, vanadate, is usually reduced to vanadyl (vanadium IV) under physiological conditions (23). Vanadate seems to be more toxic for living systems, and its conversion to vanadyl has been proposed as a detoxification mechanism $(24,25)$. Because of its anabolic properties, vanadyl sulfate $\left(\mathrm{VOSO}_{4}\right)$ has been used by athletes and body builders to improve performance in weight-training athletes with neither adverse effects on several blood parameters nor evidence of its effectiveness (6). However, the ability of cardiac myocytes to attenuate the toxicity of vanadate by rapidly reducing vanadate to vanadyl before inducing irreversible effects remains speculative at present. Willsky and Dosch (26) showed the relevance of mitochondrial function (oxidative phosphorylation) in vanadium metabolism, since yeast respiratory-deficient 
strains accumulated higher amounts of vanadate compounds. More recently, in previous works (27-30), we have shown that the mitochondria of liver and heart tissues are the subcellular organelles with higher contents in vanadium in animals treated with in-blood injections of monovanadate or decavanadate solutions.

Different vanadate oligomers can promote different effects in biological systems in vitro $(28,31-33)$ and in vivo (27-31, 34-37). However, it is not clear what the signaling pathways followed by different oligomeric forms are. The predominant form of vanadium in biological fluids at $\mathrm{pH} 4-8$ is monomeric vanadate $\left(\mathrm{V}_{1}\right)(38)$. Higher oligomeric species of vanadate, although they are not present under physiological conditions, may be present in toxic vanadium concentrations or in special cellular compartments where vanadium accumulation takes place. Stankiewicz et al. (39) proposed that decameric vanadate $\left(\mathrm{V}_{10}\right)^{1}$ is the vanadate oligomer with more biochemical relevance. Several studies have reported that $\mathrm{V}_{10}$ is a more potent inhibitor of several enzymes than other vanadate oligomers (28). Furthermore, it has been suggested that $\mathrm{V}_{10}$ binding to specific proteins may prevent its decomposition into smaller vanadate oligomers (33). However, only a few studies have dealt in detail with the biological effects of decavanadate solutions under physiological conditions. In fact, because of its stability at physiological conditions $(27,28,30,35-37), \mathrm{V}_{10}$ species may not be completely deoligomerized into other oligovanadates before inducing changes in several stress markers. Indeed, our group has demonstrated that $\mathrm{V}_{10}$ induces stronger oxidative stress effects in the cardiac tissue than monovanadate, depressing antioxidant enzymes activity and increasing lipid peroxidation (27, 30, 32, 37). As phosphate analogues (40), vanadate oligomers have been shown to inhibit and stimulate several enzyme activities of the phosphate metabolism, such as ATPases, phosphatases, and kinases $(41,42)$.

The major aim of the present work is to further explore the contribution of different vanadate oligomers to cardiac cytotoxic effects by studying vanadate-induced cell death in neonatal rat ventricular myocytes. This paper will concentrate on the effects of different vanadate oligomers $\left(\mathrm{V}_{10}\right.$ and $\left.\mathrm{V}_{1}\right)$ on cell viability, vanadium accumulation in cells, intracellular calcium $\left(\left[\mathrm{Ca}^{2+}\right]_{\mathrm{i}}\right)$, reactive oxygen species (ROS) production, and mitochondrial membrane potential in primary cardiomyocytes in culture. It is shown that both $\mathrm{V}_{10}$ and $\mathrm{V}_{1}$ induced necrotic cell death in primary cardiomyocytes in culture.

\section{Experimental Procedures}

Primary Cardiomyocyte Cell Culture and Vanadate Treatments. Ventricles from hearts of neonatal (2 days old) Wistar rats (Rattus norvegicus) were dissociated with pancreatin and collagenase. The cell culture protocol used was a modification of the methods described by Chlopcikova et al. (43). Briefly, the cells

${ }^{1}$ AAS, atomic absorption spectroscopy; Ac-DEVD-CHO, caspase-3 substrate; Ac-DEVD-pNA, Ac-DEVD- $p$-nitroaniline, a specific caspase-3 inhibitor; AraC, cytosine- $\beta$-D-arabinofuranoside; BSA, bovine serum albumin; $\left[\mathrm{Ca}^{2+}\right]_{\mathrm{i}}$, intracellular calcium; DCF, dichlorofluorescein; DHE, dihydroethidium; DIV, days in vitro; DMEM, Dulbecco's modified Eagle's medium; DMSO, dimethylsulfoxide; EC, energy charge; EPR, electron paramagnetic resonance; FITC, fluorescein 5 -isothiocyanate; fura-2 AM, fura-2-acetoxymethyl ester; $\mathrm{H}_{2} \mathrm{DCFDA}$, dichlorodihydrofluorescein diacetate; JC-1, 3,3',6,6'-tetrachloro-1,1',3,3'-tetraethylbenzimidazolcarbocyanine iodide; MTT, 3-(4,5-dimethylthiazol-2-yl)-2,5-diphenyltetrazolium bromide; MV, metavanadate solution; MTP, mitochondrial transition pore; TMRE, tetramethylrhodamine ethyl ester; TORT-2, lobster hepatopancreas marine reference material for trace metals; $\mathrm{V}_{1}$, monomeric vanadate; $\mathrm{V}_{2}$, dimeric vanadate; $\mathrm{V}_{4}$, tetrameric vanadate; $\mathrm{V}_{5}$, pentameric vanadate; $\mathrm{V}_{10}$, decameric vanadate. were resuspended in Dulbecco's modified Eagle's medium (DMEM) and medium 199 supplemented with $10 \%$ horse serum, 5\% fetal calf serum, $2 \mathrm{mM} \mathrm{L}$-glutamine, $100 \mathrm{U} / \mathrm{mL}$ penicillin, and $100 \mathrm{U} / \mathrm{mL}$ streptomycin. To selectively enrich the myocytes, dissociated cells were preplated for $2 \mathrm{~h}$ to allow nonmyocytes to attach to the bottom of the culture dish. The resultant suspension of myocytes was transferred onto $1 \%$ gelatine-coated $35 \mathrm{~mm}$ culture dishes, at a density of $1 \times 10^{6}$ cells/dish. The mitotic inhibitor cytosine- $\beta$-Darabinofuranoside (AraC), in a concentration of $20 \mu \mathrm{M}$, was added during the first $72 \mathrm{~h}$ and blocked nonmyocytes cell proliferation.

After 3 days in DMEM growth medium at $37{ }^{\circ} \mathrm{C}$ in a humidified atmosphere with $5 \% \quad \mathrm{CO}_{2} / 95 \%$ air, the cardiomyocytes were switched to serum-free medium. Cells were maintained afterward in serum-free DMEM supplement with $50 \mathrm{U} / \mathrm{mL}$ penicillin and 50 $\mathrm{U} / \mathrm{mL}$ streptomycin and treated with decavanadate $\left(\mathrm{V}_{10}\right)$ or metavanadate (MV) concentrations ranging from 0 to $50 \mu \mathrm{M}$ (total vanadium). All experiments were performed using cardiomyocytes at 3-4 DIV (days in vitro).

Detection of Vanadate Oligomers and Vanadate Bioreduction. The vanadate oligomers present in $\mathrm{V}_{10}$ and $\mathrm{MV}$ solutions used on cardiomyocytes vanadium treatments were measured by ${ }^{51} \mathrm{~V}$ nuclear magnetic resonance (NMR) spectroscopy in a Bruker AM-400 spectrometer at $105.2 \mathrm{MHz}$ equipped with a $5 \mathrm{~mm}$ multinuclear inverse probe, by using a $90^{\circ}$ pulse Fourier transform technique. Spectra were acquired at room temperature using 0.5 $\mathrm{mL}$ of vanadate samples in serum-free medium (DMEM) in the absence and presence of neonatal rat cardiomyocytes, containing at least $10 \% \mathrm{D}_{2} \mathrm{O}$, under the following conditions: spectral width, $45455 \mathrm{~Hz}$; acquisition time, $0.05 \mathrm{~s}$; and relaxation delay, $0.01 \mathrm{~s}$. Chemical shifts reported are relative to an external reference of $\mathrm{VOCl}_{3}(0 \mathrm{ppm})$. The relative areas of the several free and bound vanadate resonances were integrated, and the line widths were obtained after subtracting the value $(20 \mathrm{~Hz})$ used in line broadening. The concentration of vanadate oligomers $\mathrm{V}_{x}$ was calculated from the fractions of the total integrated areas observed in the recorded spectra using the following equation: $\left[\mathrm{V}_{x}\right]=\left(A_{x} / A_{\mathrm{t}}\right) \cdot\left(\left[\mathrm{V}_{\mathrm{t}}\right] / n\right)$, where the symbol $A$ corresponds to the area measured for the $x$ vanadate species with the $n$ aggregation number (number of vanadium atoms), $A_{\mathrm{t}}$ is the sum of measured areas, and $\left[\mathrm{V}_{\mathrm{t}}\right]$ corresponds to total vanadate concentration, as described elsewhere $(30,35,37)$. The calculated concentrations of vanadate oligomers were reproducible within $2-4 \%$. For quantitative measurements, all spectra parameters were kept constant.

Vanadate reduction products were recorded by electron paramagnetic resonance (EPR) in a Bruker EMX-300 computerized spectrometer at $9.654 \mathrm{GHz}$ (X-band) equipped with an Oxford cryostat (ESR900). The reduced vanadium spectrum in serum-free DMEM, in the absence or presence of rat cardiac myocytes, was acquired using $2 \mathrm{~mW}$ microwave potency and a $5 \mathrm{Gpp}$ modulation amplitude. The spectra were recorded at $77 \mathrm{~K}$ temperature in 0.2 $\mathrm{mL}$ of samples with the typical EPR spectral parameters: receptor gain, $1.0 \times 10^{5}$; and four scans averaged, as described previously (37).

Cell Viability. The estimation of viable cells was assessed by measuring the amount of colored formazan formed upon the reduction of 3-(4,5-dimethylthiazol-2-yl)-2,5-diphenyltetrazolium bromide (MTT) by the mitochondrial dehydrogenase activity present in live cells, as described previously $(44,45)$. Formazan was dissolved in dimethylsulfoxide (DMSO), and the differences in absorbance between 490 and $700 \mathrm{~nm}$ were measured.

Additionally, a direct estimation of viable cardiomyocytes was obtained through a modified double-staining technique (46). Briefly, culture medium was discarded, attached cells were washed with phosphate-buffered saline (PBS), and a stock solution of bisbenzimide (Hoechts 33258 at $10 \mathrm{mg} / \mathrm{mL}$ ) was added to dishes, yielding a final concentration of $0.3 \mathrm{mg} / \mathrm{mL}$ in $\mathrm{K} 5$ Locke's buffer, during $30 \mathrm{~min}$ at $37^{\circ} \mathrm{C}$. Upon incubation, bisbenzimide was discarded and the cells were washed with PBS. To the same dishes, a stock solution of propidium iodide $(10 \mathrm{mg} / \mathrm{mL})$ was added, yielding a final concentration of $10 \mu \mathrm{g} / \mathrm{mL}$, during the final $5 \mathrm{~min}$ of staining. Bisbenzimide- (stains genetic material) and propidium iodide- 
stained (indicates necrotic cells) cultures washed in PBS were examined and photographed, using a Nikon Diaphot 300 inverted microscope. Filters for propidium iodide fluorescence used a 550 $\mathrm{nm}$ wavelength, and for bisbenzimide, a 420-505 nm wavelength was used. Vanadate-induced cell death was measured in resuspended propidium iodide-stained cells. Propidium iodide fluorescence was examined in a fluorimeter using $535 \mathrm{~nm}$ excitation and $617 \mathrm{~nm}$ emission wavelengths. The fluorescence intensity was recorded after the addition of $0.1 \%$ Tween-20, and at the end, 5 $\mu \mathrm{g} / \mathrm{mL}$ of propidium iodide was added as a positive internal standard control. Fluorescence measurements were carried out with a PerkinElmer 650-40 spectrophotometer, equipped with a thermostatic cell holder under continuous magnetic stirring.

Caspase-3 Activity and Energy Charge (EC). The caspase-3 activity was measured using Ac-DEVD- $p$-nitroaniline (Ac-DEVDpNA), as described in Samhan-Arias et al. (45). The culture medium was discarded, attached cells were washed with PBS, and lysates from two plates were obtained with $50 \mathrm{mM}$ Hepes, pH 7.4, 100 $\mathrm{mM} \mathrm{NaCl}, 0.1 \mathrm{mM}$ EDTA, $5 \mathrm{mM}$ DTT, and 0.1\% CHAPS as lysis buffer. After removal of nonlysed material, caspase-3 activity was measured in the following buffer: $50 \mathrm{mM}$ Hepes, $\mathrm{pH} 7.4,100 \mathrm{mM}$ $\mathrm{NaCl}, 1 \mathrm{mM}$ EDTA, $5 \mathrm{mM}$ DTT, 0.1\% CHAPS, and 10\% glycerol, and $0.2 \mathrm{mM}$ of caspase-3 substrate (Ac-DEVD-CHO) was added to the cuvette. The activity was calculated spectrophotometrically (at $405 \mathrm{~nm}$ ) using an extinction coefficient for $p$-nitroaniline of $10500 \mathrm{M}^{-1} \mathrm{~cm}^{-1}$ and with Ac-DEVD-CHO as a specific caspase-3 inhibitor. Caspase-3 human recombinant was used as a positive control.

EC, a quantitative estimation of the energy status of the cell, was assessed by determining the in vivo concentration of nucleotides. Adenine nucleotides were determined spectrophotometrically as described in Estabrook et al. (47) after extraction with perchloric acid $(3.3 \%)$ and neutralization with $\mathrm{KOH}(44)$. The extent of absorbance was related to that obtained with standard solutions of ATP, ADP, and AMP, and the concentration of adenine nucleotides was directly determined. Cell EC was calculated according to the following equation: $(\mathrm{ATP}+0.5 \mathrm{ADP}) /(\mathrm{ATP}+\mathrm{ADP}+\mathrm{AMP})$. Absorbance measurements were done with spectrophotometers (Koron, Shimadzu) equipped with thermostatted cell holders.

Cellular Vanadium Uptake. Cellular vanadium uptake was measured as described previously (29). Briefly, after they were washed three times with Locke's buffer, cardiomyocytes were resuspended and digested with $65 \% \mathrm{HNO}_{3}$ at $100{ }^{\circ} \mathrm{C}$. After digestion, the residue was resuspended with $500 \mu \mathrm{L}$ of $10 \% \mathrm{HCl}$. The vanadium concentration was determined by atomic absorption spectroscopy (AAS) using a GBC Avanta atomic absorption spectrometer, equipped with a GBC GF 3000 graphite furnace system, with a GBC PAL 3000 autosampler, working at a furnace program of $63 \mathrm{~s}$ with an argon gas flow of $3.0 \mathrm{~L} / \mathrm{min}$. The vanadium lamp was operated at $318.2 \mathrm{~nm}$, with a slit width of $0.2 \mathrm{~nm}$, and the instrument was calibrated against a series of solutions containing $5,10,15$, and $20 \mathrm{ppb}$ of vanadium. Calibrating standards were obtained by successive dilutions of a Merck standard solution of vanadium $1002 \pm 2 \mathrm{mg} / \mathrm{L}$. The detection and quantification limits of the instrument for these analysis conditions, determined according ISO 8466-1, were $5 \pm 1$ and $14 \pm 3 \mathrm{ppb}$, respectively.

The accuracy of the method was determined through analysis of the certified reference material lobster hepatopancreas marine reference material for trace metals (TORT-2) (certified vanadium content $1.64 \pm 0.19 \mathrm{mg}$ vanadium $/ \mathrm{kg}$ ). Vanadium recovery ranged from 92 to $110 \%$ of the certified value. Precision was also acceptable, ranging from 8 to $10 \%$, as percent relative standard deviation, for this method.

Measurements of Intracellular $\mathrm{Ca}^{2+}$ in Cardiomyocytes. $\left[\mathrm{Ca}^{2+}\right]_{\mathrm{i}}$ was measured as indicated in previous papers $(45,48,49)$. Briefly, isolated neonatal rat cardiomyocytes were loaded with the fluorescent indicator, fura-2-acetoxymethyl ester (fura-2 AM) by incubation in DMEM for 90 min with $5 \mu \mathrm{g} / \mathrm{mL}$ fura- $2 \mathrm{AM}$ and $0.025 \%$ pluronic-F127 at $37^{\circ} \mathrm{C}$. Afterward, myocytes were washed twice with K25-Locke's buffer and the culture dish was placed in a thermostatic-controlled plate (Warner Instrument Co., Hamden,
CT) of a Nikon Diaphot 300 inverted microscope, equipped with an epifluorescence attachment and excitation filter wheel. To measure the $\left[\mathrm{Ca}^{2+}\right]_{\mathrm{i}}$ concentration, ratio fluorescence images were obtained with excitation filters of 340 and $380 \mathrm{~nm}$ and a dichroic mirror DM510 and absorption filter (emission side) of $510 \mathrm{~nm}$. Digital images were taken with a Hamamatsu Hisca CCD camera and Lambda 10-2 filter wheel controller and subsequently analyzed with the Argus/Hisca software. $\left[\mathrm{Ca}^{2+}\right]_{\mathrm{i}}$ was calculated as described by Thomas and Delaville (50), with the equation: $\left[\mathrm{Ca}^{2+}\right]_{\mathrm{i}}=K_{\mathrm{d}}[(R$ $\left.\left.-R_{\min }\right) /\left(R_{\max }-R\right)\right] \cdot \beta$, where $R$ is the measured fluorescence ratio (340/380) and $R_{\max }$ and $R_{\min }$ are the ratio values (340/380) for $\mathrm{Ca}^{2+}$-bound and $\mathrm{Ca}^{2+}$-free fura- 2 in loaded cardiomyocytes. $R_{\max }$ and $R_{\min }$ were experimentally determined from steady-state fluorescence ratio (340/380) measurements after sequential addition to the culture medium of fura-2-loaded cardiac myocytes of (i) $\operatorname{BrA} 23187(5 \mu \mathrm{g} / \mathrm{mL})$ or ionomycin $(45 \mu \mathrm{g} / \mathrm{mL})$ and (ii) $10 \mathrm{mM}$ EGTA, respectively. The average values obtained for $R_{\max }$ and $R_{\min }$ were $3.2 \pm 0.2$ and $0.20 \pm 0.02(n>500$ cells $)$, respectively, and the obtained average value for the ratio of fluorescence values for $\mathrm{Ca}^{2+}$-free/ $/ \mathrm{Ca}^{2+}$-bound indicator at $380 \mathrm{~nm}(\beta)$ was $1.85 \pm 0.15$. A value of $224 \mathrm{nM}$ has been used for $K_{\mathrm{d}}$, the dissociation constant of the complex fura-2: $\mathrm{Ca}^{2+}(50)$.

Measurement of Intracellular Oxidative Stress. Dichlorodihydrofluorescein diacetate $\left(\mathrm{H}_{2} \mathrm{DCFDA}\right)$ staining was used as a measure of whole intracellular oxidative stress $(51,52)$. At three DIV, cardiomyocytes were switched to K5 Locke's buffer plus the indicated additions of vanadate solutions ranging from 0 to $50 \mu \mathrm{M}$ total vanadium concentration, and after 12 or $24 \mathrm{~h}$, the cultures were incubated for $10 \mathrm{~min}$ with $10 \mu \mathrm{M} \mathrm{H}_{2}$ DCFDA. The fluorescence of $\mathrm{H}_{2}$ DCFDA-loaded cells was monitored with a CCD camera (Hamamatsu), mounted on a Nikon Diaphot 300 inverted microscope using a $470 \mathrm{~nm}$ excitation filter and DM510 dichroic mirror with a 510 emission barrier filter. The exposure time for each intensity image acquisition was set close to $0.1 \mathrm{~s}$. Acquired images were analyzed using ARGUS/HiSCA software (Hamamatsu).

Dihydroethidium (DHE) is a specific dye for superoxide anion $\left(\mathrm{O}_{2}{ }^{-}\right)(53)$. Cells were treated with vanadate ranging from 0 to 50 $\mu \mathrm{M}$ for 12 or $24 \mathrm{~h}$ and loaded with DHE $(10 \mu \mathrm{M}$ final concentration from a $10 \mathrm{mM}$ stock solution in DMSO) for $10 \mathrm{~min}$ at $37{ }^{\circ} \mathrm{C}$ in Locke's buffer. The harvested cells were washed with PBS twice. Cell fluorescence images were acquired using the Hamamatsu CCD camera mounted on the Nikon Diaphot 300 inverted microscope, with an excitation filter of $470 \mathrm{~nm}$ plus a dichroic mirror DM580 and a barrier emission filter of $590 \mathrm{~nm}$, and later analyzed with the Hamamatsu ARGUS/HiSCA software. The exposure time for each intensity image acquisition was set close to $0.1 \mathrm{~s}$.

All experiments were performed at $37^{\circ} \mathrm{C}$. The mean fluorescence intensity was calculated by averaging area intensities from at least 100 cells. For each condition described, images from several fields of the plates were collected and all of the experiments were done in triplicate (using three different preparations of cardiomyocytes).

Measurement of $\Delta \psi_{m}$ with Fluorescent Indicators 3,3',$6,6^{\prime}$-Tetrachloro-1, $1^{\prime}, 3,3^{\prime}$-tetraethylbenzimidazolcarbocyanine iodide (JC-1) and Tetramethylrhodamine Ethyl Ester (TMRE). Mitochondrial membrane potential $\left(\Delta \psi_{\mathrm{m}}\right)$ was monitored in cardiomyocytes with either JC-1 or TMRE. Cells were stained with JC-1 $(2 \mu \mathrm{M})$ at $37{ }^{\circ} \mathrm{C}$ for $30 \mathrm{~min}$ and rinsed three times with PBS solution and changed to K5 Locke's buffer (54). Cell fluorescence images were acquired using the Hamamatsu CCD camera mounted on the Nikon Diaphot 300 inverted microscope and later analyzed with the Hamamatsu ARGUS/HiSCA software. The distribution of JC-1 between monomeric and aggregate states was quantified from green and red fluorescence intensity images acquired with an excitation filter of $470 \mathrm{~nm}$ and a dichroic mirror/ barrier filter setup of 510/520 and 580/590 nm, respectively. All of the experiments were done in triplicate with at least three different preparations of cardiomyocytes and different freshly prepared vanadate solutions, and the results are the average of the intensity readings obtained for $n>100$ cells. The ratios of JC- 1 aggregate to monomer intensity for each region were calculated. 
A decrease in this ratio was interpreted as a decrease of $\Delta \psi_{\mathrm{m}}$, whereas an increase in the ratio was interpreted as a gain in $\Delta \psi_{\mathrm{m}}$ (55).

Additionally, ventricular myocytes were loaded with TMRE by incubation with a solution containing $5 \mu \mathrm{M}$ TMRE and $0.01 \%$ pluronic-F127 for $15 \mathrm{~min}$. Images were acquired as previously indicated for the red fluorescence of JC-1 (excitation filter of 470 $\mathrm{nm}$, dichroic mirror of $580 \mathrm{~nm}$, and barrier emission filter of 590 $\mathrm{nm})$. The exposure time for each intensity image acquisition was set close to $0.1 \mathrm{~s}$.

Protein Concentration and Statistical Analysis. The protein concentration was determined by the method of Bradford (56) using the Bio-Rad (Hercules, $\mathrm{CA}$ ) protein assay reagent and bovine serum albumin (BSA) as a standard. All data were obtained in at least three independent experiments with replicates of three or more for each condition. Results are expressed as means \pm standard errors (SE). Statistical analysis was carried out by a Mann-Whitney nonparametric test. The significant difference was accepted at the $P<0.05$ level.

Chemicals and Reagents. Ascorbic acid, ATP, BSA, AraC, DMEM, L-glutamine, medium 199 Hepes modification, heatinactivated fetal bovine serum (FBS, Catalog F-9665), heatinactivated horse serum (HS, Catalog H-1138), 3-[4,5-dimethylthiazol2-yl]-2,5-diphenyltetrazolium bromide (MTT), NADH, NADPH, pancreatin, and penicillin plus streptomycin were obtained from Sigma Chemical Co. (St. Louis, MO). An Annexin V-FITC (fluorescein $5^{\prime}$-isothiocyanate) apoptosis detection kit was purchased from Sigma Chemical Co. Collagenase type II was from Gibco (Paisley, United Kingdom). Glucose-6-phosphate dehydrogenase, glutathione reductase, hexokinase, lactate dehydrogenase, myokinase, and pyruvate kinase were purchased from Roche Molecular Biochemicals (Mannheim, Germany). Fura-2 AM and pluronicF127 were obtained from Molecular Probes (Eugene, OR). 2',7'$\mathrm{H}_{2}$ DCFDA was obtained from Molecular Probes (Groningen, Netherlands). Antibodies against mouse [antimyosin; antimouse IgG, peroxidase, antimouse HPR; Vimentin Ab-2 (clone V9); goat antimouse IgG-FITC] were from Santa Cruz Biotechnology (Santa Cruz, CA). Super Signal chemiluminescent substrate was from Pierce (Rockford, IL). A caspase-3 activity kit, including caspase-3 human recombinant, was purchased from Calbiochem (San Diego, CA). TORT-2 (1.64 $\pm 0.19 \mathrm{mg}$ vanadium $/ \mathrm{kg})$ was purchased from the National Research Council of Canada.

Standard Locke's buffer contained $154 \mathrm{mM} \mathrm{NaCl}, 4 \mathrm{mM}$ $\mathrm{NaHCO}_{3}, 5 \mathrm{mM} \mathrm{KCl}, 2.3 \mathrm{mM} \mathrm{CaCl}_{2}, 1 \mathrm{mM} \mathrm{MgCl}_{2}, 5 \mathrm{mM}$ glucose, and $10 \mathrm{mM}$ Hepes ( $\mathrm{pH}$ 7.4). Other chemicals were of the highest purity available and purchased from Sigma-Aldrich (St. Louis, MO).

Vanadate Solutions. MV stock solution ( $50 \mathrm{mM}$, pH 6.7) was prepared from ammonium $\mathrm{MV}\left(\mathrm{NH}_{4} \mathrm{VO}_{3}\right) . \mathrm{V}_{10}$ stock solution was obtained by adjusting the $\mathrm{pH}$ of the former solution to 4.0 (57). The oligomeric composition of $\mathrm{V}_{10}$ and $\mathrm{MV}$ solutions was determined by ${ }^{51} \mathrm{~V}$ NMR spectroscopy in a Bruker AM-400 spectrometer at $105.2 \mathrm{MHz}$ equipped with a $5 \mathrm{~mm}$ multinuclear inverse probe, by using a $90^{\circ}$ pulse Fourier transform technique, as previously reported $(29,30,35)$.

\section{Results}

Oligomerization State of Vanadate Solutions in DMEM. The characterization of vanadate solutions in serum-free DMEM was achieved by ${ }^{51} \mathrm{~V}$ NMR spectroscopy, and it was observed that the spectrum of $\mathrm{V}_{10}(5 \mathrm{mM}$ total vanadium $)$ at $\mathrm{pH} 7.0$ contained mainly decameric species once the three signals from $\mathrm{V}_{10}$ are observed as follows: $\mathrm{V}_{10 \mathrm{~A}}$ at $-516 \mathrm{ppm}, \mathrm{V}_{10 \mathrm{~B}}$ at $-499 \mathrm{ppm}$, $\mathrm{V}_{10 \mathrm{C}}$ at $-425 \mathrm{ppm}$, and a very small signal at $-560 \mathrm{ppm}$, corresponding to $\mathrm{V}_{1}$ (Figure 1A). In contrast, in the MV (5 mM total vanadium) were detected $\mathrm{V}_{1}, \mathrm{~V}_{2}, \mathrm{~V}_{4}$, and also $\mathrm{V}_{5}$ species at $-560,-574,-579$, and $-587 \mathrm{ppm}$, respectively (Figure 1B), as described elsewhere (57). The concentration of each vanadate oligomer was calculated by integration of the respective areas of the NMR spectra as a function of total vanadate (see the

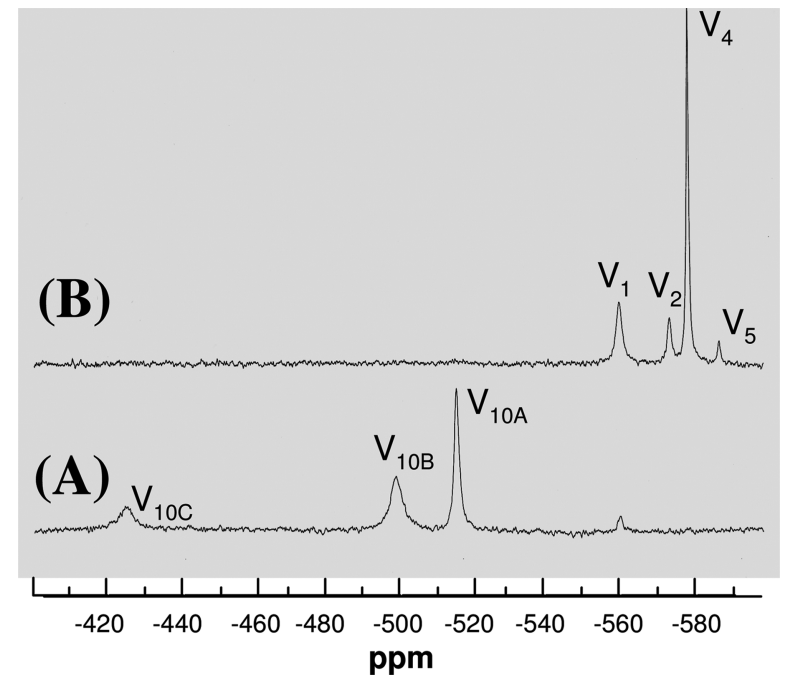

Figure 1. ${ }^{51} \mathrm{~V}$ NMR spectra of $\mathrm{V}_{10}$ and MV solutions $(5 \mathrm{mM}$ total vanadium) at room temperature. Shown are $105.2 \mathrm{MHz}{ }^{51} \mathrm{~V}$ NMR spectra of $\mathrm{V}_{10}(\mathrm{pH}$ 7.0) (A) and MV (pH 7.0) (B) solutions in DMEM. All spectra were acquired in the presence of $10 \% \mathrm{D}_{2} \mathrm{O} . \mathrm{V}_{1}$ and $\mathrm{V}_{2}$ NMR signals correspond, respectively, to $\mathrm{V}_{1}\left(\mathrm{VO}_{4}{ }^{3-}, \mathrm{HVO}_{4}{ }^{2-}\right.$, and $\left.\mathrm{H}_{2} \mathrm{VO}_{4}{ }^{-}\right)$and $\mathrm{V}_{2}\left(\mathrm{HV}_{2} \mathrm{O}_{7}{ }^{3-}\right.$ and $\left.\mathrm{H}_{2} \mathrm{~V}_{2} \mathrm{O}_{7}{ }^{2-}\right)$ species regardless of the protonation state, whereas $\mathrm{V}_{4}$ and $\mathrm{V}_{5}$ correspond to cyclic $\mathrm{V}_{4}\left(\mathrm{~V}_{4} \mathrm{O}_{12}{ }^{4-}\right)$ and $\mathrm{V}_{5}\left(\mathrm{~V}_{5} \mathrm{O}_{15}{ }^{5-}\right)$ species. $\mathrm{V}_{10 \mathrm{~A}}, \mathrm{~V}_{10 \mathrm{~B}}$, and $\mathrm{V}_{10 \mathrm{C}}$ are signals of vanadium atoms from the decameric species.

equation in the Experimental Procedures), showing clearly different profiles for $\mathrm{V}_{10}$ and $\mathrm{MV}$ solutions (Table 1). The concentration of $\mathrm{V}_{10}$ increases linearly with the total vanadate concentration whereas MV does not, as it was previously reported (33). Different concentrations of $\mathrm{V}_{1}, \mathrm{~V}_{2}, \mathrm{~V}_{4}$, and $\mathrm{V}_{5}$ species are present when MV solutions are prepared in serumfree medium; the higher molecular vanadate oligomers are favored by increasing the total vanadate concentration, as described recently for another buffered solution (29). Whereas $5 \mathrm{mM} \mathrm{V}_{10}$ solutions contain about $480 \mu \mathrm{M} \mathrm{V}$ (i.e., $4.8 \mathrm{mM}$ total vanadium as $\mathrm{V}_{10}$ ) and $0.2 \mathrm{mM} \mathrm{V}_{1}, 5 \mathrm{mM} \mathrm{MV}$ solutions showed a large contribution of $\mathrm{V}_{4}$ and $\mathrm{V}_{2}$, for example, 1.22 $\mathrm{mM} \mathrm{V}, 0.706 \mathrm{mM} \mathrm{V}_{4}$, and $0.348 \mathrm{mM} \mathrm{V}_{2}$ (see Table 1), that is, 2.824 and $0.68 \mathrm{mM}$ total vanadium as $\mathrm{V}_{4}$ and $\mathrm{V}_{2}$, respectively.

Whereas the MV solutions, containing labile oxovanadates in rapid equilibrium, are stable after dilution in serum-free grow medium (DMEM), $\mathrm{V}_{10}$ are only moderately stable at physiological $\mathrm{pH}$, due to $\mathrm{V}_{10}$ decomposition, as analyzed by $\mathrm{UV}-$ visible spectroscopy. The decameric species deoligomerization was assessed by absorption measurements at $400 \mathrm{~nm}\left(37^{\circ} \mathrm{C}\right)$ and followed a first-order kinetic process, with a half-life time of above $120 \mathrm{~min}$ (measured with $1 \mathrm{mM}$ total vanadium concentration, that is, $100 \mu \mathrm{M} \mathrm{V}_{10}$ species in DMEM medium) (not shown). Thus, differential effects of $\mathrm{V}_{10}$ and $\mathrm{MV}$ solutions on cells in DMEM can be unambiguously attributed to $\mathrm{V}_{10}$ only for incubations up to 2-3 h. After this time period, the $\mathrm{V}_{10}$ solution contains not only $\mathrm{V}_{10}$ species but also the other species present in MV solutions, in agreement to previous findings in other buffered solutions $(27,29,30,35)$. Furthermore, it is known that MV solutions up to $100 \mu \mathrm{M}$ mostly contain $\mathrm{V}_{1}$, as described elsewhere (58). Nevertheless, it has been recently reported that $\mathrm{V}_{10}$ stabilization by cytoskeletal and transmembrane proteins can account, at least in part, for $\mathrm{V}_{10}$ effects in biological systems (33). Therefore, for longer incubations of cells with $\mathrm{V}_{10}$ solutions, only differential effects observed upon treatments with $\mathrm{V}_{10}$ vs $\mathrm{MV}$ solutions can be taken as an indication of specific effects of $\mathrm{V}_{10}$.

Purification of Neonatal Cardiomyocytes. The purity of cardiomyocytes cell cultures ( $\sim 80 \%$ of myocytes in culture) 
Table 1. ${ }^{51} \mathrm{~V}$ NMR Spectral Parameters, at Room Temperature, of the Vanadate Species Present in $\mathrm{V}_{10}(\mathrm{pH} 7)(\mathrm{A})$ and MV (pH 7) (B) (5 mM Total Vanadium) in DMEM ${ }^{a}$

\begin{tabular}{|c|c|c|c|c|c|c|c|}
\hline & \multicolumn{7}{|c|}{ vanadium $(5 \mathrm{mM})$} \\
\hline & $\mathrm{V}_{1}$ & $\mathrm{~V}_{2}$ & $\mathrm{~V}_{4}$ & $\mathrm{~V}_{5}$ & $\mathrm{~V}_{10 \mathrm{~A}}$ & $\mathrm{~V}_{10 \mathrm{~B}}$ & $\mathrm{~V}_{10 \mathrm{C}}$ \\
\hline $\begin{array}{l}\mathrm{A}: \mathrm{V}_{10} \\
\delta(\mathrm{ppm}) \\
v_{1 / 2(\mathrm{~Hz})} \\
C(\mu \mathrm{M})\end{array}$ & $\begin{array}{c}-560.3 \\
168 \\
236\end{array}$ & & & & $\begin{array}{c}-515.5 \\
130 \\
209\end{array}$ & $\begin{array}{c}-498.9 \\
393 \\
189\end{array}$ & $\begin{array}{c}-424.6 \\
431 \\
78\end{array}$ \\
\hline $\begin{array}{l}\mathrm{B}: \mathrm{MV} \\
\delta(\mathrm{ppm}) \\
\Delta v_{1 / 2(\mathrm{~Hz})} \\
C(\mu \mathrm{M})\end{array}$ & $\begin{array}{c}-560.0 \\
168 \\
1220\end{array}$ & $\begin{array}{c}-573.8 \\
130 \\
348\end{array}$ & $\begin{array}{c}-578.9 \\
55 \\
706\end{array}$ & $\begin{array}{c}-587.4 \\
55 \\
54\end{array}$ & & & \\
\hline
\end{tabular}

${ }^{a}$ Listed parameters are chemical shift $(\delta)$, half-line width $\left(\Delta v_{1 / 2}\right)$, and concentration of the respective vanadate oligomeric species $(C)$. The concentration $(C)$ of the vanadate species present in $\mathrm{V}_{10}$ and $\mathrm{MV}$ was determined from the fractions of the integrated areas observed in the corresponding spectrum (see the equation in the Experimental Procedures). $\Delta v_{1 / 2}$ values have a variation of $\pm 20 \mathrm{~Hz}$.

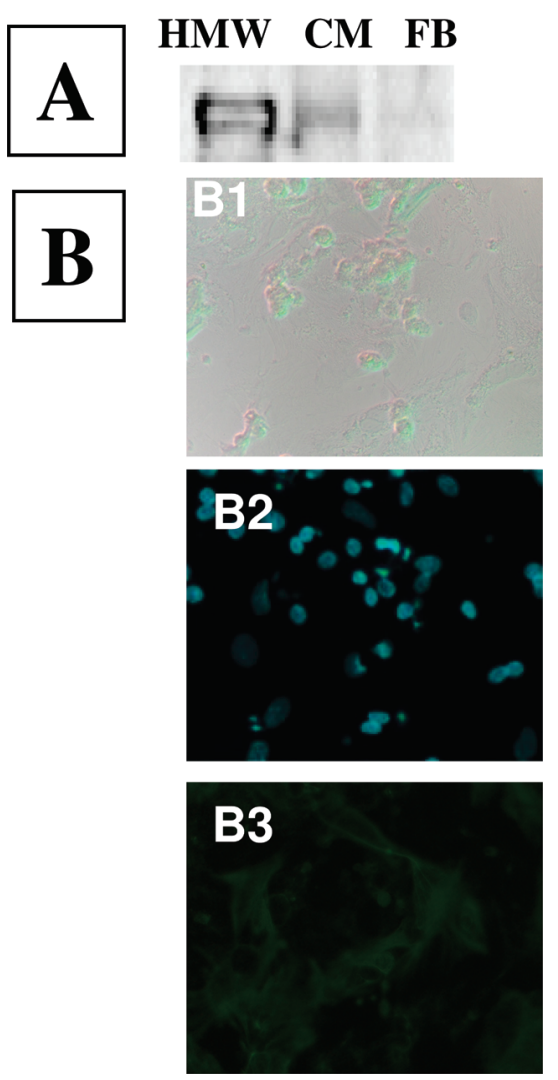

Figure 2. Markers used for the characterization of the cardiomyocytes culture. Myosin heavy chain $(200 \mathrm{kDa})$ bands detection by immunoblot in high molecular weight standard marker from Bio-Rad (HMW), cellular lysates of cardiomyocytes (CM), and cellular lysates of isolated fibroblasts (FB) (A) and immunodetection of fibroblasts in neonatal rat primary cardiomyocytes cultures (B). (A) Primary antibody antisarcomeric myosin heavy chain (1/100 dilution) and antimouse $\mathrm{IgG}$ peroxidase (1/10000 dilution) as secondary antibody. (B) B1, B2, and $\mathrm{B} 3$, phase contrast, DAPI staining, and antivimentin staining images, respectively, of a representative field of the cardiomyocytes preparation. Staining with antivimentin was performed using $10 \%$ goat serum as a blocking reagent and a Vimentin Ab-2 (clone V9) 1/50 dilution as primary antibody/goat antimouse IgG-FITC as secondary antibody. Approximately $80 \%$ of the cells identified with nuclear DAPI staining correspond to cardiomyocytes.

was estimated either by cell counting, immunodetection of myosin heavy chain, or immunostaining (Figure 2). Cardiomyocytes were easily identified microscopically by their characteristic ability to contract spontaneously and synchronously and by their morphology: Cultured cardiac cells tend to form a monolayer, although some myocytes remained isolated when the cell density in culture plates was too low. Spherical nuclei were centrally located and surrounded by relatively plentiful
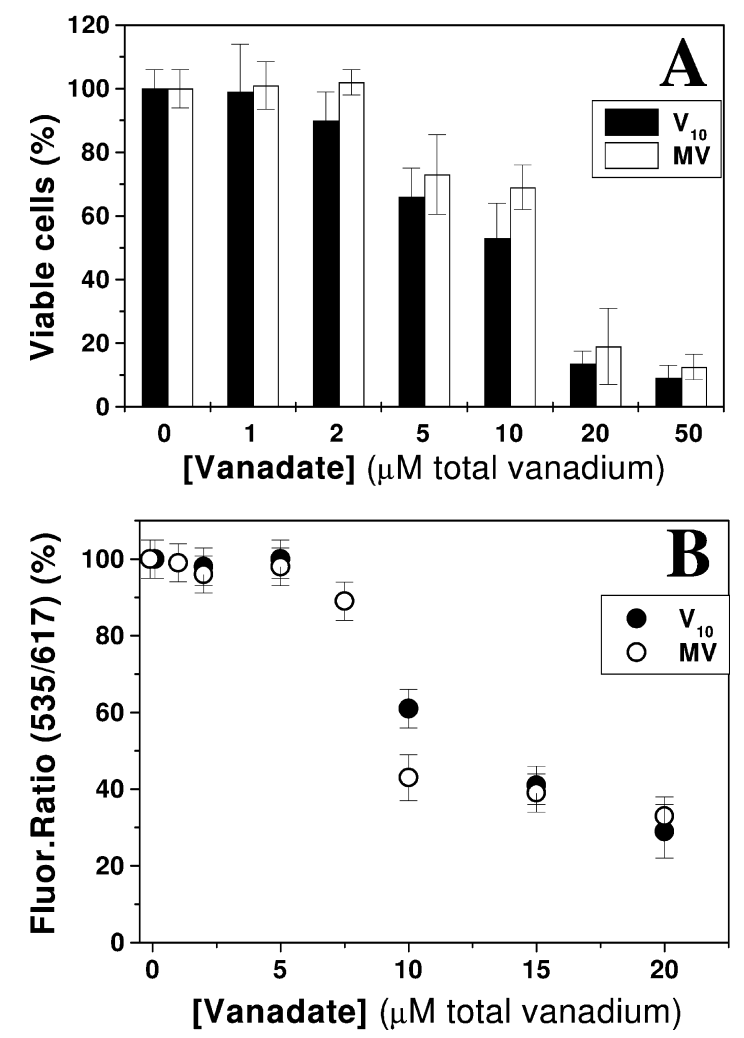

Figure 3. Viability of neonatal rat cardiomyocytes after $24 \mathrm{~h}$ of exposure to vanadate oligomers. After three DIV, cells were treated with $\mathrm{V}_{10}$ and $\mathrm{MV}$ concentrations ranging from 0 to $50 \mu \mathrm{M}$ total vanadium and the viability was assessed by MTT assay (A) and propidium iodide fluorescence (B) (means \pm SE). *Significantly different from control $(P<0.05)$.

cytoplasm packed with well-delineated myofibrils (59). Contaminating fibroblasts, besides immunocytochemical identified using Vimentin Ab-2 antibody (tested with fibroblasts Swiss $3 \mathrm{~T} 3$ before use), were readily distinguished by their spindleshaped nuclei, as well as by the absence of myofibrils.

Toxicity of Treatments with $\mathrm{V}_{10}$ and MV Solutions To Cardiomyocytes. The estimation of viable cells upon vanadate treatments was assessed by MTT viability assay and propidium iodide fluorescence, as indicated in the Experimental Procedures. Both vanadate solutions were found to decrease cell viability (Figure 3). The MTT assay indicated that $24 \mathrm{~h}$ of exposure to $\mathrm{V}_{10}$ and $\mathrm{MV}$ solutions induced a similar loss of cell viability $\left(\mathrm{LD}_{50}=10 \mu \mathrm{M}\right.$ total vanadium) (Figure $\left.3 \mathrm{~A}\right)$. It should be noted that $1 \mu \mathrm{M} \mathrm{V}_{10}$ corresponds to $10 \mu \mathrm{M}$ total vanadate, or $50 \mu \mathrm{M}$ vanadate in Figure $3 \mathrm{~A}$ corresponds to $5 \mu \mathrm{M} \mathrm{V} 10$ species. The slight differences seen in Figure $3 \mathrm{~A}$ between the loss of cell 
viability upon $24 \mathrm{~h}$ of treatment with $\mathrm{V}_{10}$ and $\mathrm{MV}$ solutions are unlikely to be significant. This conclusion rests not only on the basis of the statistical analysis of the data $(P>0.05)$ but also due to the fact that the loss of cell viability after $12 \mathrm{~h}$ of exposure of cardiomyocytes to $\mathrm{V}_{10}$ and $\mathrm{MV}$ solutions was the same for the same total vanadium concentration.

The staining with Hoescht 33258 showed a great variability in the DNA amount extracted from vanadate-treated cardiomyocytes (not shown). The observed cell density variability between vanadate-treated and control dishes was due to the fact that detached death cells were discarded by washes. For this reason, all of the subsequent data were analyzed taking into account the protein content of each culture dish. The loss of viability monitored by propidium iodide (Figure $3 \mathrm{~B}$ ) pointed out that $\mathrm{V}_{10}$ and $\mathrm{V}_{1}$ species induced a necrotic cell death. Moreover, the extent of necrotic cell death monitored by propidium iodide closely matched the extent of cell viability monitored with the MTT assay and further reinforced that there are not significant differences between the extent of cardiomyocytes death induced by exposure to $\mathrm{V}_{10}$ and MV solutions when they are normalized to total vanadium concentration.

Although it is known that vanadate treatment in rat cardiomyocytes inhibited caspase- 3 activation induced by ischemia, thereby inhibiting apoptosis (60), the possibility of some contribution of apoptosis to the overall cell death observed in cardiomyocytes after treatment with $\mathrm{V}_{10}$ and $\mathrm{MV}$ solutions deserved to be considered. The caspase- 3 activity was measured in cardiomyocyte lysates after 3, 6, 9, 12, and $24 \mathrm{~h}$ from the application of $20 \mu \mathrm{M}$ (total vanadium) $\mathrm{V}_{10}$ or $\mathrm{MV}$. Treatment of cardiomyocytes with $20 \mu \mathrm{M}$ total vanadium as $\mathrm{V}_{10}$ or $\mathrm{MV}$ did not elicit an increase of caspase-3 activity with respect to the very small activity measured for control cardiomyocytes, that is, $100 \pm 30$ pmol per min per mg protein (data not shown). To further assess that the cell death induced by $\mathrm{V}_{10}$ or the other vanadate species present in MV solutions is not apoptotic cell death, we carried out double staining of cardiomyocytes with annexin V-FITC and propidium iodide following the manufacturer's instructions for this standard kit of apoptosis. Fluorescence microscopy images of cardiomyocytes were acquired at 6 and $12 \mathrm{~h}$ after the addition of $20 \mu \mathrm{M}$ (total vanadium) $\mathrm{V}_{10}$ or MV. They confirmed the increase of propidium iodide-stained cells in this period, as well as cells displaying double staining of propidium iodide and annexin V-FITC, but not the appearance of cardiomyocytes positively stained only with annexin V-FITC (Figure 4A). In contrast, a significant decrease of the cardiomyocytes EC was observed after $24 \mathrm{~h}$ of exposure to $\mathrm{V}_{10}: 1$ and $2 \mu \mathrm{M} \mathrm{V}_{10}$ reduced EC by -36 and $-39 \%$, respectively. Slightly lower decreases, $-(10-15) \%$ and $-(15-20) \%$, were measured for $24 \mathrm{~h}$ of exposure to the same concentrations of total vanadium added as MV [thus, cell death monitored by propidium iodide (Figure 3B)-characteristic of necrosis-and the decrease of myocytes EC led to the conclusion that the loss of cell viability observed upon vanadate exposure is largely due to necrotic cell death].

Vanadium Uptake by Cardiomyocytes. To evaluate if vanadium uptake by cardiomyocytes depends on the oligomerization state of vanadium, in the present study, we have quantified vanadium accumulation in cell extracts by AAS. To this end, after incubation with $\mathrm{V}_{10}$ and $\mathrm{MV}$ solutions in concentrations that produce a significant loss of cardiomyocytes viability, the extracellular medium was removed and cells were washed three times with $2 \mathrm{~mL}$ of Locke's K5. Neonatal rat cardiomyocytes showed a vanadium basal value of $4.341 \pm$ $0.297 \mathrm{ppb} / \mathrm{mg}$ protein. Vanadium accumulation in cell extracts

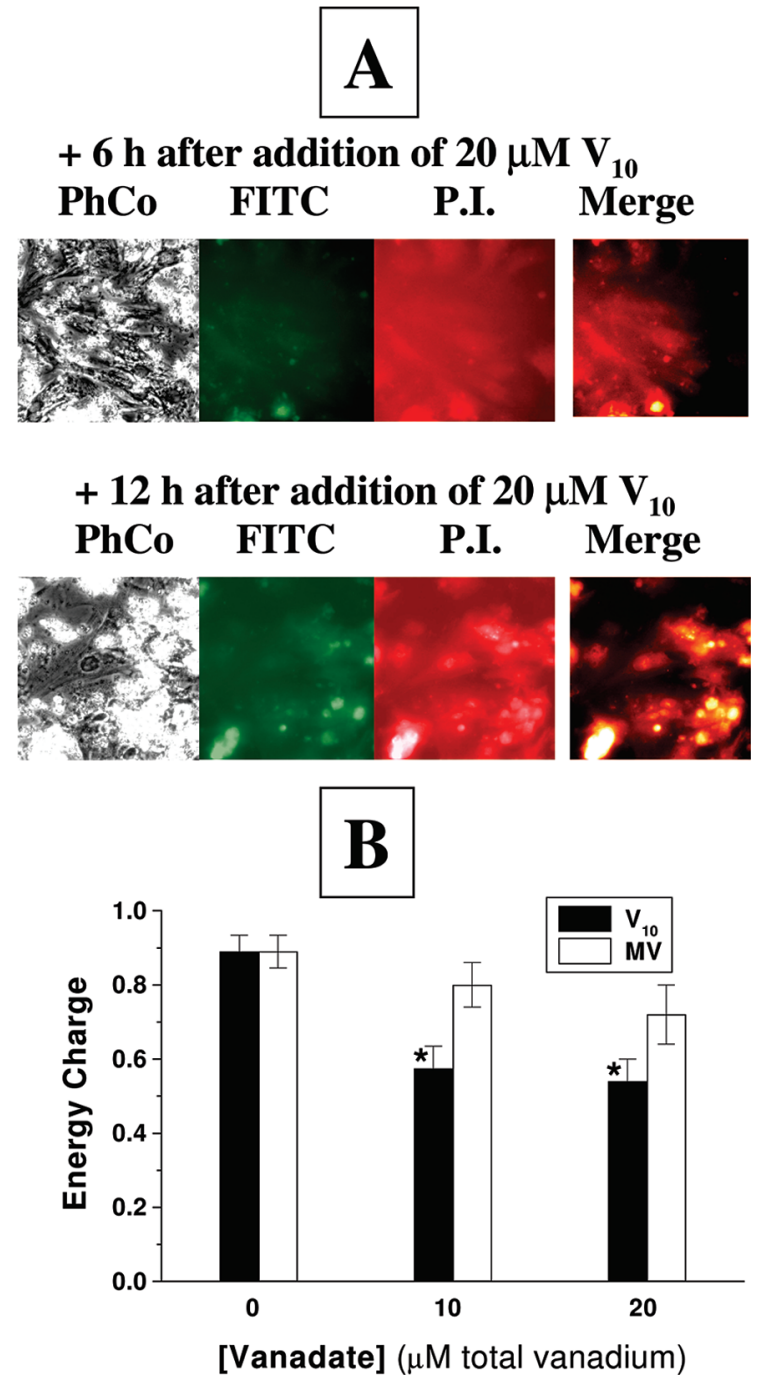

Figure 4. Evaluation of vanadate-induced cell death in neonatal rat cardiomyocytes in culture. (A) Double staining with propidium iodide and annexin V-FITC of cardiomyocytes treated with $20 \mu \mathrm{M}$ (total vanadium) $\mathrm{V}_{10}$ and MV for 6 and $12 \mathrm{~h}$. PhCo, FITC, and P.I. mean phase contrast microscopy image, annexin V-FITC, and propidium iodide fluorescence microscopy images, respectively. (B) Decrease of myocytes EC upon $24 \mathrm{~h}$ of treatment with $\mathrm{V}_{10}$ and MV concentrations ranging from 0 to $20 \mu \mathrm{M}$ total vanadium (B) (means $\pm \mathrm{SE}$ ). $*$ Significantly different from control $(P<0.05)$.

seems to increase with total vanadate concentration present in the growth medium. Treatment with $10 \mu \mathrm{M}$ (total vanadium) of $\mathrm{V}_{10}$ and $\mathrm{MV}$ solutions for $24 \mathrm{~h}$ significantly increased the content of vanadium up to $45 \pm 4$ and $60 \pm 6 \mathrm{ppb} / \mathrm{mg}$ protein, respectively. These results suggested that the $V_{1}$ (phosphate analogue) is taken up by cardiac myocytes. It was also observed that above $10 \mu \mathrm{M}$, vanadium uptake is not dependent on the oligomerization state of the vanadium solution: $24 \mathrm{~h}$ after treatment, with $\mathrm{V}_{10}$ or MV solutions, cardiomyocytes equally accumulate both oligovanadates (Figure 5). Treatment with 20 $\mu \mathrm{M}$ vanadate (total vanadium) induces an increase in the amount of vanadium near $+1400 \%$, whereas the vanadium content in cardiomyocytes treated with $50 \mu \mathrm{M}$ vanadate is increased to almost $+2000 \%$ with respect to control nontreated cells (Figure 5).

To understand the intracellular uptake and metabolism of vanadate oligomers by cardiac cells, we used a combination of EPR spectroscopy with the previous NMR studies. ${ }^{51} \mathrm{~V}$ NMR spectroscopy has provided information about the speciation of vanadate oligomers in the serum-free culture medium. Looking 
for a possible vanadium bioreduction in cells, conditioned media (supernatant) and washed cardiomyocytes were studied by means of an EPR technique. After $12 \mathrm{~h}$ of incubation of cardiomyocytes with $50 \mu \mathrm{M}$ (total vanadium) $\mathrm{V}_{10}$ or $\mathrm{MV}$ solutions, EPR signals of reduced vanadium were absent in either supernatant and washed cell culture (results not shown). Therefore, although it is known that intracellular vanadate can be reduced to vanadyl (23), we failed to detect even a weak vanadyl signal in either supernatant fractions and washed cardiomyocytes, meaning that reduced vanadium must be below the detection limit of our EPR instrument, for example, $<10$ $\mu \mathrm{M}$ reduced vanadium.

Effects of Treatments with $\mathrm{V}_{10}$ and $\mathrm{MV}$ on the $\left[\mathrm{Ca}^{2+}\right]_{i}$ Homeostasis of Surviving Cardiomyocytes. $\left[\mathrm{Ca}^{2+}\right]_{i}$ was measured using cardiomyocytes preloaded with the $\mathrm{Ca}^{2+}$ sensitive fluorescent dye, fura-2, as described in the Experimental Procedures. Control cardiac myocytes (nontreated cells) presented a normal low $\left[\mathrm{Ca}^{2+}\right]_{\mathrm{i}}$ in the range of $60 \pm 10 \mathrm{nM}$ and very large intracellular $\left[\mathrm{Ca}^{2+}\right]_{\mathrm{i}}$ peaks associated with spontaneous beating (Figure 6). Cardiomyocytes treated for $24 \mathrm{~h}$ with $\mathrm{V}_{10}$ or $\mathrm{MV}(10 \mu \mathrm{M}$ total vanadium) were able to maintain its intracellular $\mathrm{Ca}^{2+}$ homeostasis although at higher basal $\left[\mathrm{Ca}^{2+}\right]_{\mathrm{i}}$, between 200 and $250 \mathrm{nM}$, and thus, the height of their intracellular $\left[\mathrm{Ca}^{2+}\right]_{\mathrm{i}}$ peaks associated with spontaneous beating is largely reduced when compared with control untreated cardiomyocytes (Figure 6). Therefore, these results pointed out that cardiomyocytes exposure to vanadate solutions, either $\mathrm{V}_{10}$ and $\mathrm{MV}$, impaired the balance between calcium uptake and release by intracellular $\mathrm{Ca}^{2+}$ stores, favoring at least partial calcium depletion of intracellular stores.

Treatment of Cardiomyocytes with $V_{10}$ and MV Decreased Intracellular Oxidative Stress. The intracellular oxidative stress monitored by DHE was found to be largely attenuated by exposure of cardiomyocytes to both vanadate solutions (Figure 7A). DHE has been shown to be more sensitive to $\mathrm{O}_{2}{ }^{--}$than to another $\operatorname{ROS}(53)$. On average, a $24 \mathrm{~h}$ treatment of cardiomyocytes with $20 \mu \mathrm{M} \mathrm{V} \mathrm{V}_{10}$ (i.e., $2 \mu \mathrm{M} \mathrm{V_{10 }}$ ) or $\mathrm{MV}$ solutions reduced $\mathrm{O}_{2}{ }^{--}$production by $70 \pm 5 \%$, without significant differences between $\mathrm{V}_{10}$ and MV treatments. It has been reported that mitochondria play a major role in ROS production in living cardiomyocytes (61). This was assessed with our preparations of cardiomyocytes preloaded with $\mathrm{H}_{2} \mathrm{DCF}-$ $\mathrm{DA}$ as indicated in the Experimental Procedures, a dye that shows a much lower ROS specificity than DHE (52). The results obtained with $\mathrm{H}_{2}$ DCF-loaded cardiomyocytes demonstrated the

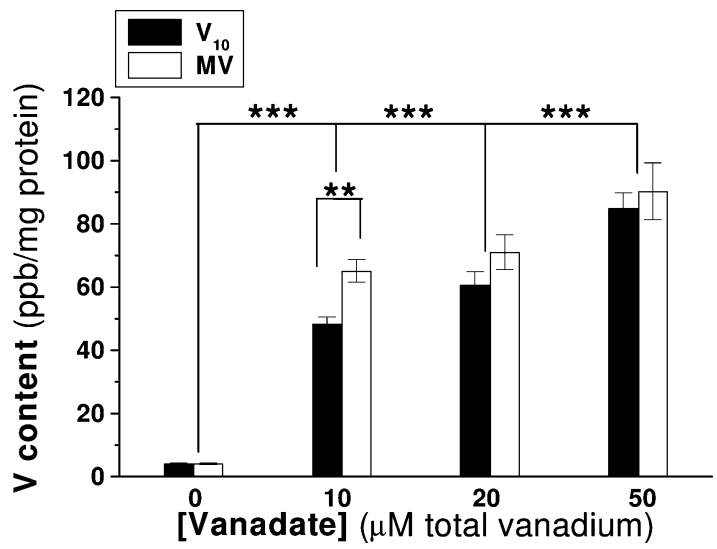

Figure 5. Vanadium uptake by cultured cardiomyocytes. Vanadium concentration (ppb V/mg protein) on neonatal rat cardiomyocytes $24 \mathrm{~h}$ after treatment with $\mathrm{V}_{10}$ and MV solutions ranging from 0 to $50 \mu \mathrm{M}$ total vanadium (means $\pm \mathrm{SE}$ ). **Significantly different from control $(P<0.01)$. *** Significantly different from control $(P<0.001)$.
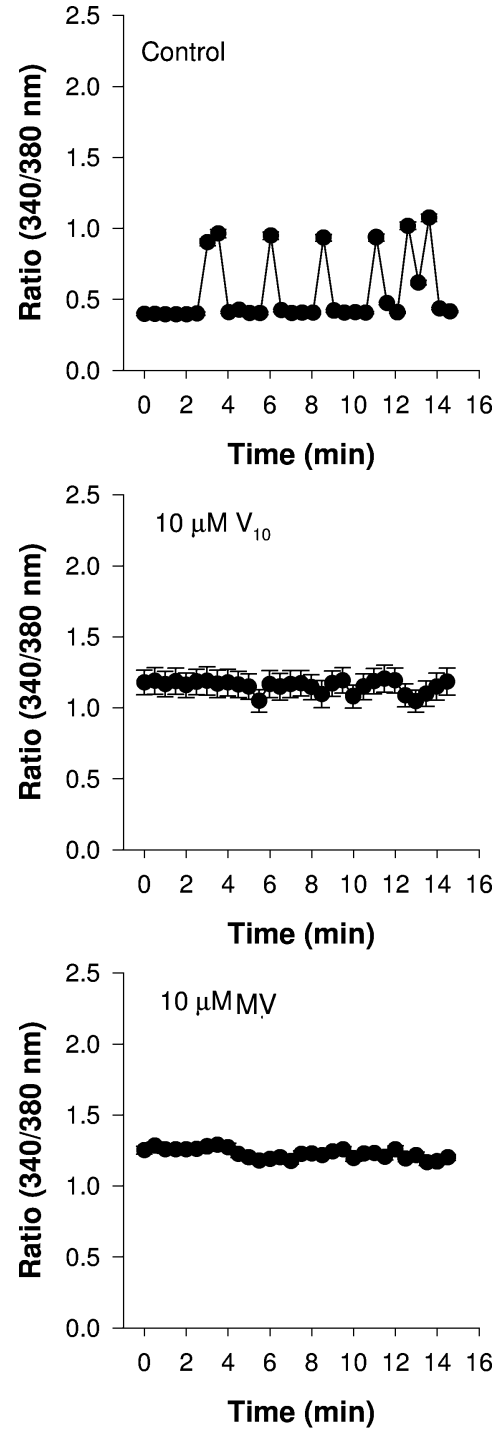

Figure 6. Effects of cardiomyocytes exposure to $\mathrm{V}_{10}$ and MV solutions $\left(10 \mu \mathrm{M}\right.$ total vanadium) on cytosolic $\mathrm{Ca}^{2+}$ homeostasis. In all of the cases, cardiomyocytes were incubated for $24 \mathrm{~h}$ with $\mathrm{V}_{10}$ or $\mathrm{MV}$, then cardiomyocytes were loaded with Fura-2 AM as indicated in the Experimental Procedures, changed to K5 Locke's medium, and transferred to the thermostatted plate of the Nikon Diaphot 300 epifluorescence microscope. Ratios (340/380) were obtained from fluorescence images acquired with excitation filters of 340 and 380 $\mathrm{nm}$ as indicated in the Experimental Procedures. The results shown (means \pm SE) are the averages of triplicate experiments ( $n \geq 20$ cells).

large spatial overlap between the appearance of dichlorofluorescein (DCF) fluorescence and the fluorescence of the mitochondrial staining dye JC-1 (Figure 7B), in good agreement with the results reported with the mitochondrial marker MitoTracker Red in Swift and Sarvazyan (62). Moreover, treatment of cardiomyocytes with $5 \mu \mathrm{M}$ FCCP, which is known to be an effective agent for depolarizing the mitochondria of cardiomyocytes (63), produced nearly $90 \%$ blockade of the oxidation rate of $\mathrm{H}_{2}$ DCF-loaded within cardiomyocytes (data not shown). As $\mathrm{O}_{2}{ }^{--}$is the one-electron reduction product of molecular oxygen, this antioxidant effect of $\mathrm{V}_{10}$ and $\mathrm{MV}$ is in agreement with the inhibition of oxygen consumption by both vanadate solutions previously reported for cardiac and hepatic mitochondria $(37,64)$. A decrease of the amount of $\mathrm{O}_{2}{ }^{--}$generated will in turn leads to a decreased production of $\mathrm{H}_{2} \mathrm{O}_{2}$, as $\mathrm{O}_{2}{ }^{--}$can be considered its metabolic precursor (65). 


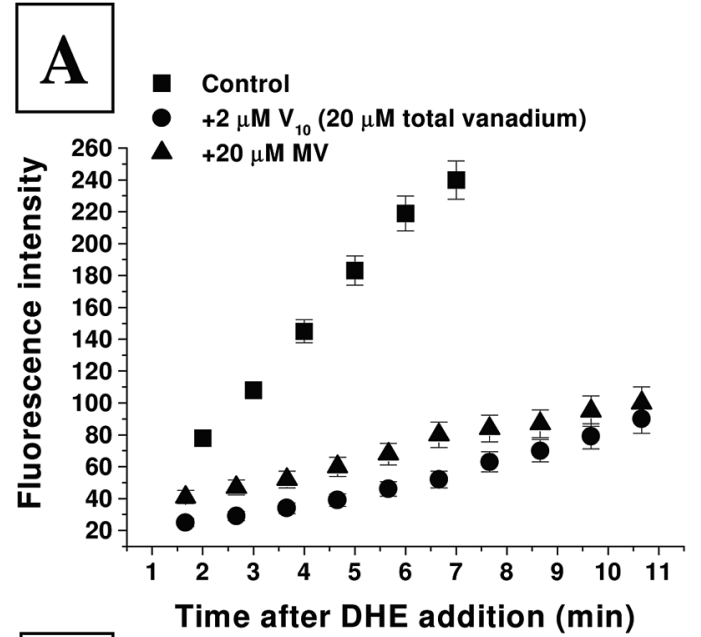

\section{B}
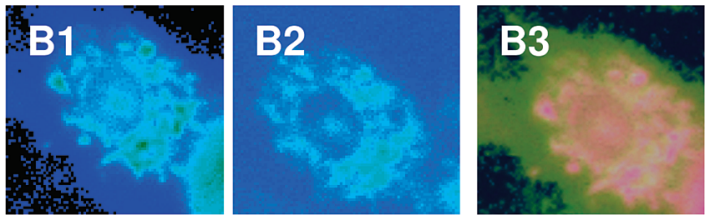

Figure 7. Effect of $\mathrm{V}_{10}$ and MV solutions on the rate of DHE oxidation by cardiomyocytes. (A) Kinetics of oxidation of DHE by control cardiomyocytes (squares) and cardiomyocytes incubated $24 \mathrm{~h}$ with $\mathrm{V}_{10}$ (circles) or MV (up-triangles). Cardiomyocytes were changed to a prethermostatted K5 Locke's medium and placed in the plate holder of the microscope thermostatted at $37{ }^{\circ} \mathrm{C}$, and the kinetics was started by addition of $10 \mu \mathrm{M}$ DHE. The kinetic data shown are the average of triplicate experiments $(n \geq 100$ cells, means \pm SE). Fluorescence intensity readings were taken from time-sequential fluorescence intensity images acquired with a CCD Hamamatsu camera mounted on a Nikon Diaphot 300 inverted epifluorescence microscope (excitation filter 470 $\mathrm{nm}$; dichroic mirror $580 \mathrm{~nm}$, and emission barrier filter $590 \mathrm{~nm}$ ) and analysed with the Argus/Hisca software. (B) Localization of hydrogen peroxide production in cardiomyocytes labelled with $10 \mu \mathrm{M} \mathrm{H}_{2} \mathrm{DCF}-$ DA (B1) and $2 \mu \mathrm{M}$ JC-1-stained cells (B2), and merge of the two previous images highlighted ROS (mostly hydrogen peroxides) production in mitochondria (B3).

Treatment of Cardiomyocytes with $\mathrm{V}_{10}$ and MV Produced Mitochondrial Depolarization. Maintenance of the mitochondrial membrane potential $\left(\Delta \psi_{\mathrm{m}}\right)$ is essential for the normal performance and survival of cells with a high metabolic energy requirement, such as cardiomyocytes. The mitochondrial membrane potential plays a major role in the modulation of calcium uptake and release by mitochondria in rat ventricular myocytes (66). In addition, mitochondria depolarization with the protonophore FCCP results in a large decrease of ROS production by cardiomyocytes; see above. In this study, $\Delta \psi_{\mathrm{m}}$ was initially measured in ventricular myocytes with the fluorescent indicator JC-1. Fluorescence images of cardiomyocytes stained with JC-1 (Figure 8) showed that control cells exhibited heterogeneous staining of the cytoplasm with both red (polarized mitochondria) and green (depolarized mitochondria) fluorescence coexisting in the same cell (Figure 8A, top panels). Consistent with mitochondrial localization, the red fluorescence was mostly found in rod-shaped and granular structures distributed throughout the cytoplasm. The green fluorescence followed a similar pattern but overall gave a more blurred image, suggesting also some extramitochondrial localization. Superimposition of the red and green fluorescence images revealed a large degree of overlap (orange-yellow color). A minority of mitochondria, though, exhibited only green fluorescence; these were most conspicuous in areas of cytoplasm surrounding the nucleus. Pretreatment of cardiomyocytes with $1 \mu \mathrm{M} \mathrm{V}_{10}$ (i.e., $10 \mu \mathrm{M}$ total vanadium) for $24 \mathrm{~h}$ (Figure 8A, bottom panels) had a dramatic effect on the red fluorescence, which then became very faint. In contrast, it caused a slight but noticeable increase in the green fluorescence intensity but did not affect the distribution substantially. As a result, the superimposed images showed only a few mitochondria stained with orange, with the majority exhibiting green or yellow-green fluorescence. Similar results were obtained with MV solutions, although it required slightly higher concentrations, $20-50 \mu \mathrm{M}$ total vanadium (data not shown).

Because of the large heterogeneity observed in cardiomyocytes stained with JC-1 (Figure 8B), we used TMRE-loaded cardiomyocytes for a more reliable quantification of $\mathrm{V}_{10^{-}}$and $\mathrm{V}_{1}$-induced mitochondrial membrane depolarization. TMREloaded cardiomyocytes showed a more homogeneous response to either $\mathrm{V}_{10}$ or MV solutions (Figure 9A). The dependence of the average TMRE fluorescence vs the concentration of vanadate normalized to total vanadium (Figure 9B) clearly showed that after $24 \mathrm{~h}$ of incubation with cardiomyocytes, both $\mathrm{V}_{10}$ and MV induced a dose-dependent depolarization of mitochondria, with a similar $\mathrm{IC}_{50}$ value of $6.5 \pm 1 \mu \mathrm{M}$ total vanadium. Figure $9 \mathrm{~B}$ also shows that up to $2 \mu \mathrm{M}$ total vanadium incubation of cardiomyocytes for $24 \mathrm{~h}$ with the vanadate solutions used (MV and $\mathrm{V}_{10}$ ) did not produce a significant mitochondria depolarization. Figure 9C shows that a large decrease of the fluorescence of TMRE-loaded cardiomyocytes is seen between 6 and $9 \mathrm{~h}$ after the application of $20 \mu \mathrm{M}$ (total vanadium) of $\mathrm{V}_{10}$ and MV to cardiomyocytes, while only $30 \%$ loss of cell viability is seen after $12 \mathrm{~h}$. The large standard error at $6 \mathrm{~h}$ after addition of $\mathrm{V}_{10}$ and MV is due to the presence of a mixed population of cells with polarized and completely depolarized mitochondria. Therefore, a large and sustained vanadate-induced mitochondrial depolarization precedes the loss of cell viability and the possibility that this could be mediated by opening of the mitochondrial transition pore (MTP) deserved to be considered. However, vanadate-induced depolarization in purified mitochondria $(37,64)$ is not prevented by cyclosporin A (data not shown). Moreover, the MTP blocker cyclosporin A did not protect against the loss of cell viability and mitochondrial depolarization after the treatment of cardiomyocytes with 20 $\mu \mathrm{M}$ (total vanadium) $\mathrm{V}_{10}$ or $\mathrm{MV}$, as this was the same in the absence and in the presence of the following concentrations of cyclosporin A: $0.1,0.5$, and $1 \mu \mathrm{M}$. Therefore, the possibility that vanadate-induced mitochondrial depolarization and cell death can be due to vanadate-induced opening of the MTP is unlikely.

\section{Discussion}

The results reported in this paper clearly show that exposure to micromolar vanadate solutions can be very harmful to cardiomyocytes, as only $24 \mathrm{~h}$ of incubation of ventricular neonatal rat myocytes is sufficient to induce cell death with an $\mathrm{IC}_{50}$ of approximately $10 \mu \mathrm{M}$ total vanadium. Because $10 \mathrm{~mol}$ of total vanadium contains $1 \mathrm{~mol}$ of $\mathrm{V}_{10}$ species, this implies that only $1 \mu \mathrm{M} \mathrm{V}_{10}$ is needed to produce nearly $50 \%$ cardiomyocytes cell death. Furthermore, a noticeable cell death is already observed after $24 \mathrm{~h}$ of incubation with $2 \mu \mathrm{M}$ total vanadium, that is, $0.2 \mu \mathrm{M} \mathrm{V}_{10}$ or $2 \mu \mathrm{M} \mathrm{V}_{1}$. The exposure of cardiomyocytes to different oligomeric states of vanadium (from $\mathrm{V}_{1}$ to $\mathrm{V}_{10}$ ) was almost equally harmful to these cells, as shown by the overlap of the dependence of the extent of cell death attained upon 12 and $24 \mathrm{~h}$ of exposure upon the total vanadium 

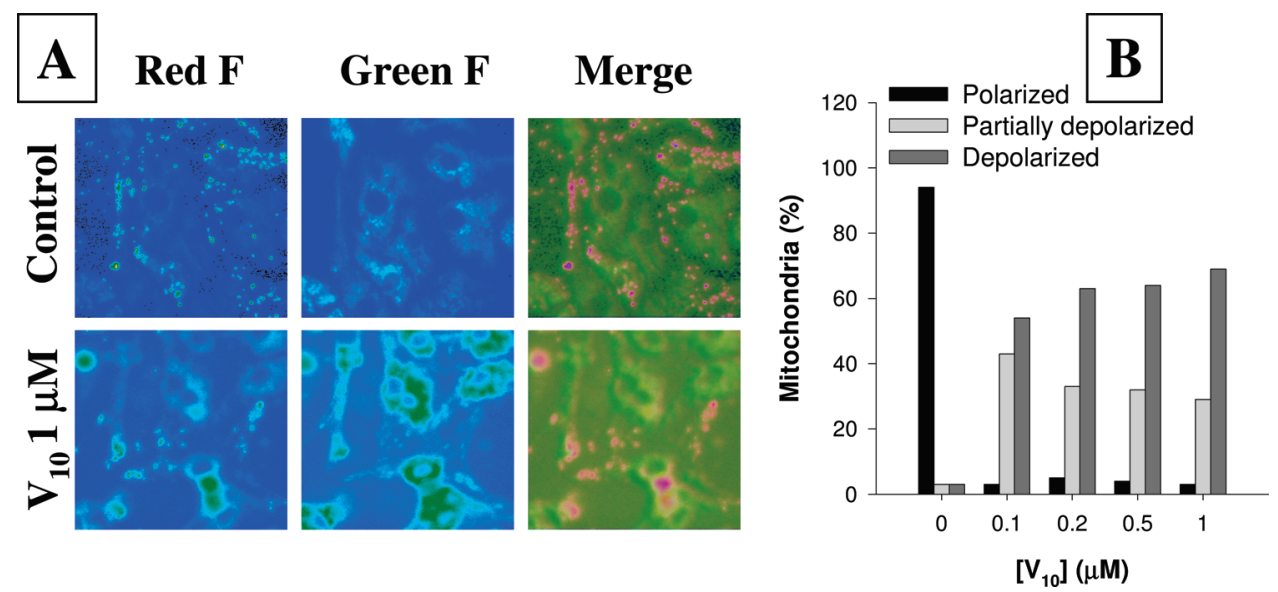

Figure 8. Effect of $\mathrm{V}_{10}$ and MV solutions on the fluorescence of cardiomyocytes stained with JC-1. (A) Cardiomyocytes were grown on 35 mm dishes and stained with $0.6 \mu \mathrm{M} \mathrm{JC}-1$ in the absence (control) and presence of $1 \mu \mathrm{M} \mathrm{V} \mathrm{V}_{10}(10 \mu \mathrm{M}$ total vanadium concentration). Left and middle panels show representative images of the aggregate (red) and monomer (green) fluorescence of the same field, respectively. The right panels show the merge of the two images; in this case, the yellow/orange-red color denotes colocalization of red and green fluorescence signals. (B) Average results (means \pm SE) of the quantification of pseudocolored pixels in merge images like those shown in panel 8A ( $n \geq 100$ cells, experiments done by triplicate). Red pixels were taken for polarized mitochondria, yellow/orange for partially polarized mitochondria, and green pixels for depolarized mitochondria. *Significantly different from control $(P<0.05)$.

concentration added from $\mathrm{V}_{10}$ or MV solutions. Thus, the results presented in this paper further support the concerns over the potential risk of the use of vanadium compounds in athletes as a sport supplement $(7,8)$ and also for the possible use of these compounds in the chemotherapy of multidrug-resistant tumors, as suggested by some authors (67-69). In previous works, we have reported that the heart is one of the tissues displaying higher vanadium content after chronic administration of $\mathrm{V}_{10}$ and MV $(29,30,32,34)$. Because vanadium is slowly eliminated from mammalian tissues $(21,22)$, chronic consumption of even very low doses of vanadium compounds may eventually reach the toxic levels to cardiomyocytes, and this would elicit a rapid and irreversible heart damage, which may appear like a "sudden death" due to heart failure. Because of this, only low vanadiumcontaining food products should be allowed for human nutrition and it is a high-risk practice to use vanadium compounds as a sport supplement or in therapeutical treatments.

Two different widely used methods, MTT assay and propidium iodide staining, have been used to assess the loss of cell viability upon exposure of cardiomyocytes to both $V_{10}$ and MV solutions. As propidium iodide staining is a widely accepted marker for necrotic cell death, this possibility was further confirmed by the measurement of the decrease of the cellular $\mathrm{EC}$ of cardiomyocytes upon exposure to $\mathrm{V}_{10}$ solutions. The lack of activation of caspase-3 and of phosphatidylserine externalization (monitored with annexin V-FITC) during vanadateinduced cardiomyocytes cell death pointed out that death through apoptosis does not afford a significant contribution to this cell death.

In spite of the very different size of $\mathrm{V}_{10}$ (the predominant oligomeric vanadium species present in the $\mathrm{V}_{10}$ solutions used in this study) and $\mathrm{V}_{1}$ (predominant vanadium species in the MV solutions at the vanadate concentration used in this work), the amount of vanadium incorporated into these cells was roughly identical after $24 \mathrm{~h}$ of incubation of cardiomyocytes with $\mathrm{V}_{10}$ and MV. Taking into account that no plasma membrane transport system has been reported yet for $\mathrm{V}_{10}$ and also the halflife time of approximately $2 \mathrm{~h}$ for decomposition of $\mathrm{V}_{10}$ in the medium used for cardiomyocytes culture (DMEM), the simple hypothesis to account for similar levels of vanadium uptake by cardiomyocytes after $24 \mathrm{~h}$ of incubation with $\mathrm{V}_{10}$ and $\mathrm{MV}$ is that incorporation of vanadium into the cells takes place by transport of the less bulky $\mathrm{V}_{1}$ through the plasma membrane, which is known to permeate through mammalian phosphate transport systems (23). Although it has been reported that $\mathrm{V}_{1}$ can be reduced to vanadyl inside the cells (23), possibly as part of a detoxification mechanism $(24,25)$, EPR measurements done with the cardiomyocyte cultures used in this study failed to detect vanadyl, meaning that this specie is below the EPR detection limit under the experimental conditions used in this work.

In earlier works, we have shown that vanadium accumulation in mitochondria is higher than that found in other subcellular organelles of liver and heart tissues extracted from whole animals that were injected with $\mathrm{V}_{10}$ or MV solutions (27-30). Mitochondria are known to also be a major $\left[\mathrm{Ca}^{2+}\right]_{\mathrm{i}}$ store in cardiomyocytes (76) and also a major compartment for superoxide anion and other ROS production in cardiomyocytes (77). The intracellular pattern of fluorescence staining upon oxidation of $\mathrm{H}_{2} \mathrm{DCF}$ within our cardiomyocyte preparations clearly demonstrated the mitochondrial relevance for ROS production in our cell cultures because the spatial intracellular regionalization of DCF fluorescence staining showed a large overlap with the spatial intracellular regionalization obtained with the fluorescence mitochondrial membrane potential probe JC-1. This is in excellent agreement with Swift and Sarvazyan (62), who reported that $\mathrm{H}_{2} \mathrm{DCF}$ is a marker of oxidative stress in cardiac muscle, which displays a preferential localization of the fluorescence of oxidized DCF in mitochondria. Superoxide anion can be considered a side product ROS of mitochondrial respiration (53), and DHE has been shown to be a good fluorescence dye to measure the production of superoxide anion by mitochondria (53). We report herein that the rate of superoxide anion production within ventricular rat myocytes is only $30 \pm 5 \%$ that of control myocytes after $24 \mathrm{~h}$ of incubation of cardiomyocytes with $20 \mu \mathrm{M}$ (total vanadium) $\mathrm{V}_{10}$ or MV. This result is highly consistent with the inhibition by both $\mathrm{V}_{10}$ and MV solutions of oxygen consumption in freshly isolated rat liver and fish heart mitochondria in standard respiration buffer $(37,64,78)$. Although a decrease of ROS production can be seen as a beneficial effect of vanadate in cardiomyocytes, inhibition of the mitochondrial respiratory chain can lead to sustained mitochondrial depolarization, which is lethal for cells demanding a high supply of metabolic energy, such as cardi- 

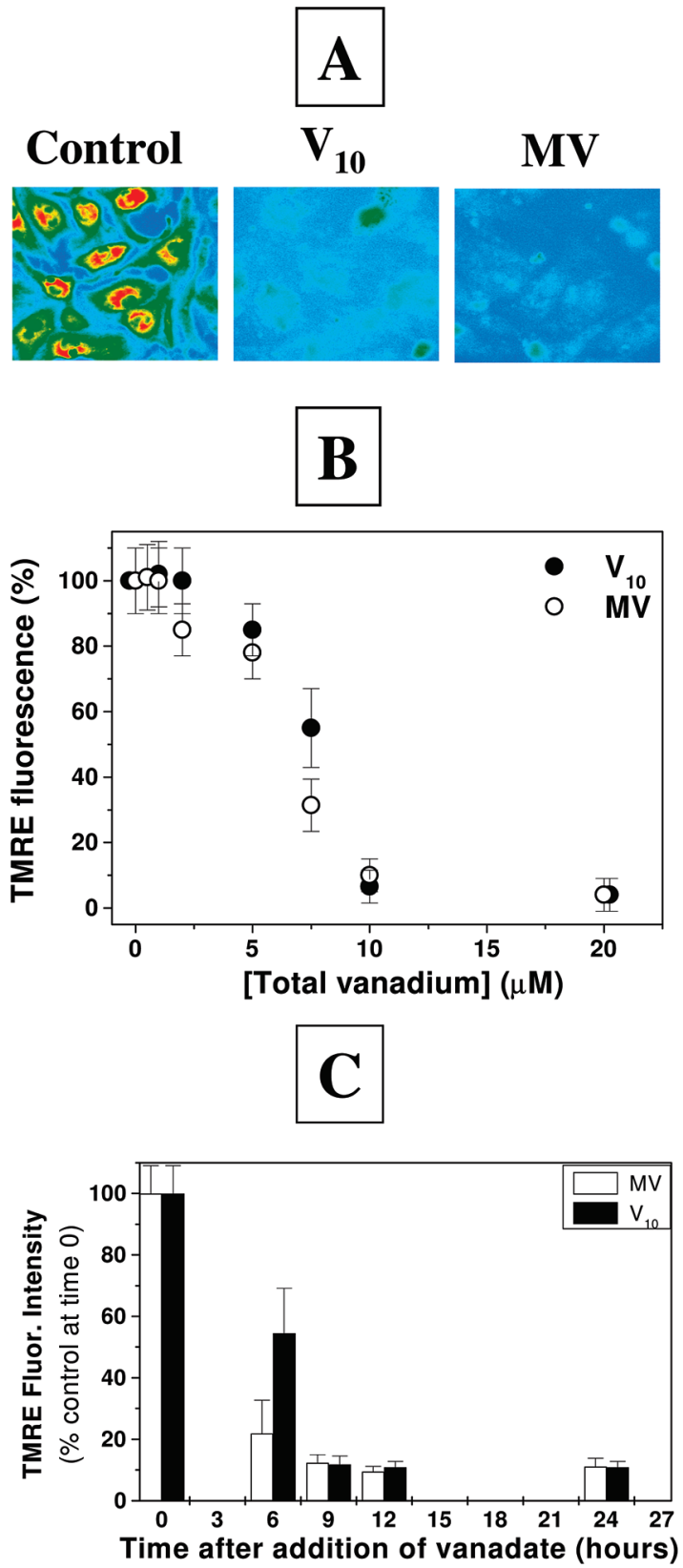

Figure 9. Effect of $\mathrm{V}_{10}$ and $\mathrm{MV}$ solutions on the fluorescence of TMRE-loaded cardiomyocytes. (A) Representative pseudocolored images of TMRE-stained myocytes are shown as follows: control and cardiomyocytes treated during $24 \mathrm{~h}$ with $20 \mu \mathrm{M}$ vanadate as $\mathrm{V}_{10}$ and MV. (B) Dependence of the intensity of the fluorescence of TMREloaded cardiomyocytes upon the $\mathrm{V}_{10}$ (solid circles) and MV concentrations (open circles) used in the $24 \mathrm{~h}$ incubation period before loading cells with TMRE. The results shown are the average (means \pm SE) of experiments done by triplicate ( $n \geq 100$ cells). (C) Dependence of the intensity of the fluorescence of TMRE-loaded cardiomyocytes upon the time after addition of $20 \mu \mathrm{M}$ (total vanadium) $\mathrm{V}_{10}$ and $\mathrm{MV}$. The results shown in panels $\mathrm{B}$ and $\mathrm{C}$ are the averages (means $\pm \mathrm{SE}$ ) of experiments done by triplicate ( $n \geq 100$ cells).

omyocytes. Thus, the effect of incubation with $\mathrm{V}_{10}$ or MV solutions on the mitochondrial membrane potential $(\Delta \Psi \mathrm{m})$ in cardiomyocytes deserved to be studied.

Both the TMRE and the carbocyanine dye JC-1 have been shown to monitor the collapse of $\Delta \Psi \mathrm{m}$ in cells in culture $(54,79)$. In this work, we show that both TMRE and JC-1 can be used to monitor vanadate-induced mitochondria depolarization. On average, the results obtained with TMRE did not show significant differences between exposure to the same total vanadium concentration added as $\mathrm{V}_{10}$ or MV. In this study, we show that a $24 \mathrm{~h}$ incubation of cardiomyocytes with $\mathrm{V}_{10}$ and MV solutions induce the collapse of $\Delta \Psi \mathrm{m}$, with the same $\mathrm{IC}_{50}$ value of $6.5 \pm 1 \mu \mathrm{M}$ total vanadium (i.e., $0.65 \pm 0.1 \mu \mathrm{M} \mathrm{V} \mathrm{V}_{10}$ or $6.5 \pm 1 \mu \mathrm{M} \mathrm{V}_{1}$ ). Therefore, the $\mathrm{IC}_{50}$ value for $\mathrm{V}_{10^{-}}$and MVinduced mitochondrial membrane depolarization is only slightly lower than the value obtained for vanadate-induced $50 \%$ loss of cell viability $\left(\mathrm{LD}_{50}=10 \mu \mathrm{M}\right.$ total vanadium). In addition, depolarization of mitochondria is clearly observed from $6 \mathrm{~h}$ after addition of $\mathrm{V}_{10}$ or $\mathrm{MV}$ to cardiomyocytes, and a sustained collapse of $\Delta \Psi \mathrm{m}$ can be seen after $9 \mathrm{~h}$, whereas only $30 \pm$ $10 \%$ loss of cell viability is seen after $12 \mathrm{~h}$ of treatment with $20 \mu \mathrm{M}$ (total vanadium) $\mathrm{V}_{10}$ or $\mathrm{MV}$. This is fully consistent with a leading role of mitochondrial depolarization in vanadateinduced cardiomyocytes death. In previous works, we have shown that vanadate can also elicit depolarization of purified mitochondria $(37,64)$. The MTP opening is unlikely to be the molecular event underlying vanadate-induced mitochondrial depolarization because cyclosporin A, an established MTP blocker in cardiomyocytes (80), cannot prevent vanadateinduced depolarization of mitochondria nor vanadate-induced cardiomyocytes death.

It has been extensively shown that a sustained increase of cytosolic calcium promotes rapid necrotic cell death in myocytes through activation of calpains (81). The basal cytosolic $\mathrm{Ca}^{2+}$ of surviving cardiomyocytes, that is, those still showing spontaneous beating, increased from $60 \pm 10$ to $200-250 \mathrm{nM}$ upon $24 \mathrm{~h}$ of incubation with $10 \mu \mathrm{M}$ (total vanadium) $\mathrm{V}_{10}$ or MV. Because this value is close to the peak cytosolic $\mathrm{Ca}^{2+}$ reached during spontaneous beating in control cardiomyocytes (250-300 $\mathrm{nM}$ ), the peak height observed during beating was largely attenuated in cardiomyocytes incubated with $\mathrm{V}_{10}$ or $\mathrm{MV}$ with respect to control cardiomyocytes. The high sensitivity of the sarco/endoplasmic $\mathrm{Ca}^{2+}$ pumps to monovanadate is welldocumented, $K_{\mathrm{i}}=0.5 \pm 0.1 \mu \mathrm{M}(70)$, thus providing a simple explanation for the sustained rise of basal cytosolic $\mathrm{Ca}^{2+}$ concentration after incubation with vanadate solutions. Also, these results are in good agreement with earlier studies that have shown vanadate-induced increased intracellular $\mathrm{Ca}^{2+}$ in cultured aortic smooth muscle cells, thereby affecting the vascular tone (71). It has also been reported that vanadate stimulates the adenylate cyclase activity in many cell types $(15,82)$. In the heart, the increased concentrations of $3^{\prime}-5^{\prime}$-cyclic adenosine monophosphate (cAMP) cause release of $\mathrm{Ca}^{2+}$ from intracellular stores, leading to an increase of heart rate and cardiac inotropism and to vasodilatation (72-75). Furthermore, mitochondrial membrane depolarization is likely underlying the observed rise of basal cytosolic calcium and partial depletion of $\left[\mathrm{Ca}^{2+}\right]_{\mathrm{i}}$ stores upon incubation of cardiomyocytes with $\mathrm{V}_{10}$ or MV solutions, as mitochondria membrane depolarization leads to mitochondrial calcium release $(83)$ and also $\mathrm{IP}_{3}$-mediated endoplasmic reticulum release in cardiomyocytes (84). Thus, our results strongly suggest that mitochondrial membrane depolarization is a key event in $\mathrm{V}_{10^{-}}$and $\mathrm{MV}$-induced cardiomyocytes death.

In conclusion, exposure to micromolar concentrations of vanadate (added from $\mathrm{V}_{10}$ or MV solutions) induces cell death in isolated neonatal rat ventricular myocytes through a similar toxic pathway, leading to mitochondrial membrane depolarization and resulting in necrotic cell death.

Acknowledgment. We are grateful to Ascensión Alonso (Group of Bioenergetics in Neurones and Myocytes, Department of Biochemistry and Molecular Biology, Faculty of Sciences, University of Extremadura) for dedicated technical assistance. We gratefully acknowledge Dr. Hélio Martins for the excellent 
technical assistance provided at the Laboratorio de Espectroscopia de Absorção Atómica (Departamento de Química e Bioquímica, FCT, Universidade do Algarve), Dr. Maria do Rosário Caras Altas for the excellent technical assistance provided at the Laboratório de Ressonância Magnética Nuclear (Departamento de Química, Universidade Nova de Lisboa), and Dr. Rui O. Duarte (Departamento de Química, Universidade Nova de Lisboa) for his help with EPR measurements. This work was supported by the POCTI program funded through FEDER, research project POCTI/38191/QUI/2001, by Joint SpanishPortuguese Grant HP2004-0080 (to C.G.-M. and M.A.), and by Grant 3PR05A078 of the Junta de Extremadura. S.S.S. was supported by a Ph.D. grant (SFRH/BD/8615/2002) from the Portuguese Foundation for Science and Technology.

\section{References}

(1) Conde, A. G., Lau, S. S., Dillmann, W. H., and Mestril, R. (1997) Induction of heat shock proteins by tyrosine kinase inhibitors in rat cardiomyocytes and myogenic cells confers protection against simulated ischemia. J. Mol. Cell Cardiol. 29, 1927-1938.

(2) Mackay, K., and Mochly-Rosen, D. (2000) Involvement of a p38 mitogen-activated protein kinase phosphatase in protecting neonatal rat cardiac myocytes from ischemia. J. Mol. Cell Cardiol. 32, 15851588.

(3) Takada, Y., Hashimoto, M., Kasahara, J., Aihara, K., and Fukunaga, K. (2004) Cytoprotective effect of sodium orthovanadate on ischaemia/ reperfusion - induced injury in the rat heart involves AkT activation and inhibition of fodrin breakdown and apoptosis. J. Pharmacol. Exp. Ther. 311, 1249-1255.

(4) Josephson, L., and Cantley, L. C. (1977) Isolation of a potent (NaK)ATPase inhibitor from striated muscle. Biochemistry 16, 4572-4578.

(5) Barbagallo, M., Dominguez, L. J., and Resnick, L. M. (2001) Insulinmimetic action of vanadate: Role of intracellular magnesium. Hypertension 38, 701-704.

(6) Fawcett, J. P., Farquhar, S. J., Walker, R. J., Thou, T., Lowe, G., and Goulding, A. (1996) The effect of oral vanadyl sulphate on body composition and performance in weight-training athletes. Int. J. Sport Nutr. 6, 382-390.

(7) Gerrard, D. F., Fawcett, J. P., and Farquhar, S. J. (1993) Vanadium use by athletes. N. Z. Med. J. 106, 259.

(8) Fawcett, J. P., Farquhar, S. J., Thou, T., and Shand, B. I. (1997) Oral vanadyl sulphate does not affect blood cells, viscosity or biochemistry in humans. Pharmacol. Toxicol. 80, 202-206.

(9) Yin, X., Davidson, A. J., and Tsang, S. S. (1992) Vanadate-induced gene expression in mouse C127 cells: Roles of oxygen derived active species. Mol. Cell. Biochem. 115, 85-96.

(10) Stern, A., Yin, X., Tsang, S. S., Davidson, A., and Moon, J. (1993) Vanadium as a modulator of cellular regulatory cascades and oncogene expression. Biochem. Cell Biol. 71, 103-112.

(11) Bay, B. H., Sit, K. H., Paramanantham, R., and Chan, Y. G. (1997) Hydroxyl free radicals generated by vanadyl [IV] induce cell blebbing in mitotic human Chang liver cells. Biometals 10, 119-122.

(12) Ye, J.-P., Ding, M., Leonard, S. S., Robinson, V. A., Millecchia, L., Zhang, X., Castranova, V., Vallyathan, V., and Shi, X. (1999) Vanadate induces apoptosis in epidermal JB6 Pplus cells via hydrogen peroxidemediated reactions. Mol. Cell. Biochem. 202, 9-17.

(13) Capella, L. S., Alcantara, J. S. M., Moura-Neto, V., Lopes, A. G., and Capella, M. A. M. (2000) Vanadate is toxic to adherent-growing multidrug-resistant cells. Tumour Biol. 21, 54-62.

(14) Capella, L. S., Gefé, M. A., Silva, E. F., Affonso-Mitidieri, O., Lopes, A. G., Rumjanek, V. M., and Capella, M. A. M. (2002) Mechanisms of vanadate-induced cellular toxicity: role of cellular glutathione and NADPH. Arch. Biochem. Biophys. 406, 65-72.

(15) Etcheverry, S. B., and Cortizo, A. N. (1998) Bioactivity of vanadium compounds on cells in culture. In Vanadium in the Environment, Part 1: Chemistry and Biochemistry (Nriagu, J. O., Ed.) pp 359-395, John Wiley \& Sons, Inc., New York.

(16) Trudel, S., Pâquet, M. R., and Grinstein, S. (1991) Mechanism of vanadate-induced activation of tyrosine phosphorylation and of the respiratory burst in HL60 cells. Role of reduced oxygen metabolites. Biochem. J. 276, 611-619.

(17) Volberg, T., Zick, Y., Dror, R., Sabanay, I., Gilon, C., Levitzki, A., and Geiger, B. (1992) The effect of tyrosine-specific protein phosphorylation on the assembly of adherens-type junctions. EMBO J. 11, 1733-1742.
(18) Secrist, J. P., Burns, L. A., Karnitz, L., Koretzky, G. A., and Abraham, R. T. (1993) Stimulatory effects of the protein tyrosine phosphatase inhibitor, pervanadate, on T-cell activation events. J. Biol. Chem. 268, 5886-5893.

(19) Harland, B. F., and Harden-Williams, B. A. (1994) Is vanadium of human nutritional importance yet? J. Am. Diet. Assoc. 94, 891-894.

(20) Barceloux, D. G. (1999) Vanadium. Clin. Toxicol. 37, 265-278.

(21) Thompson, K. H., Battell, M., and McNeill, J. H. (1998) Toxicology of vanadium in mammals. In Vanadium in the Environment, Part 2: Health Effects (Nriagu, J. O., Ed.) pp 21-37, John Wiley \& Sons, Inc., New York.

(22) Anke, M., Illing-Günther, H., Güntler, H., Holzinger, S., Jaritz, M., Anke, S., and Schäfer, U. (2000) Vanadium-An essencial element for animals and humans? In Trace Elements in Man and Animals (Roussel, A. M., Anderson, R. A., and Favrier, A. E., Eds.) pp 221225, Kluwer Academic/Plenum Publishers, New York.

(23) Rehder, D. (1995) Inorganic considerations on the function of vanadium in biological systems. Met. Ions Biol. Syst. 31, 1-43.

(24) Sabbioni, E., Pozzi, G., Pintar, A., Casella, L., and Garattini, S. (1991) Cellular retention, cytotoxicity and morphological transformation by vanadium(IV) and vanadium(V) in BALB/3T3 cell lines. Carcinogenesis 12, 47-52.

(25) Sabbioni, E., Pozzi, G., Devos, S., Pintar, A., Casella, L., and Fischbach, M. (1993) The intensity of vanadium(V)-induced cytotoxicity and morphological transformation in BALB/3T3 cells is dependent on glutathione-mediated bioreduction to vanadium(IV). Carcinogenesis 14, 2565-2568.

(26) Willsky, G. R., and Dosch, S. F. (1986) Vanadium metabolism in wild type and respiratory-deficient strains of S. cerevisiae. Yeast 2, $77-85$.

(27) Aureliano, M., Joaquim, N., Sousa, A., Martins, H., and Coucelo, J. M. (2002) Oxidative stress in toadfish (Halobatrachus didactylus) cardiac muscle: Acute exposure to vanadate oligomers. J. Inorg. Biochem. 90, 159-165.

(28) Aureliano, M., and Gândara, R. M. C. (2005) Decavanadate effects in biological systems. J. Inorg. Biochem. 99, 979-985.

(29) Soares, S. S., Martins, H., and Aureliano, M. (2006) Vanadium distribution following decavanadate administration. Arch. Environ. Contam. Toxicol. 50, 60-64.

(30) Soares, S. S., Martins, H., Duarte, R. O., Moura, J. J. G., Coucelo, J., Gutiérrez-Merino, C., and Aureliano, M. (2007) Vanadium distribution, lipid peroxidation and oxidative stress markers upon decavanadate in vivo administration. J. Inorg. Biochem. 101, 80-88.

(31) Tiago, T., Aureliano, M., and Gutiérrez-Merino, C. (2004) Decavanadate binding to a high affinity site near the catalytic centre inhibits F-Actin-stimulated myosin ATPase activity. Biochemistry 43, 55515561.

(32) Aureliano, M., Soares, S. S., Tiago, T., Ramos, S., and GutiérrezMerino, C. (2007) Biological effects of decavanadate: Muscle contraction, in vivo oxidative stress, and mitochondrial toxicity. In Vanadium: The Versatile Metal (Kustin, K., Pessoa, J. C., and Crans, D. C., Eds.) pp 249-263, ACS Symposium Series, American Chemical Society, Washington, DC.

(33) Ramos, S., Manuel, M., Tiago, T., Gândara, R. M. C., Duarte, R. O., Moura, J. J. G., Gutiérrez-Merino, C., and Aureliano, M. (2006) Decavanadate interactions with actin: Inhibition of G-actin polymerization and stabilization of decameric vanadate. J. Inorg. Biochem. 99, 1734-1743.

(34) Borges, G., Mendonça, P., Joaquim, N., Aureliano, M., and Coucelo, J. M. (2003) Acute effects of vanadate oligomers on heart, kidney, and liver histology in the Lusitanian toadfish (Halobatrachus didactylus). Arch. Environ. Contam. Toxicol. 45, 415-422.

(35) Soares, S. S., Aureliano, M., Joaquim, N., and Coucelo, J. M. (2003) Cadmium and vanadate oligomers effects on methaemoglobin reductase activity from Lusitanian toadfish: In vivo and in vitro studies. J. Inorg. Biochem. 94, 285-289.

(36) Gândara, R. M. C., Soares, S. S., Martins, H., Gutiérrez-Merino, C., and Aureliano, M. (2005) Vanadate oligomers: In vivo effects in hepatic vanadium accumulation and stress markers. J. Inorg. Biochem. 99, 1238-1244.

(37) Soares, S. S., Gutiérrez-Merino, C., and Aureliano, M. (2007) Decavanadate induces mitochondrial membrane depolarization and inhibits oxygen consumption. J. Inorg. Biochem. 101, 789-796.

(38) Nechay, B. R. (1984) Mechanisms of action of vanadium. Annu. Rev. Pharmacol. Toxicol. 24, 501-524.

(39) Stankiewicz, P. J., Tracey, A. S., and Crans, D. C. (1995) Inhibition of phosphate-metabolizing enzymes by oxovanadium (V) complexes. In Metal Ions in Biological Systems: Vanadium and Its Role in Life (Sigel H., and Sigel, A., Eds.) pp 287-324, Marcel Dekker, New York.

(40) Gresser, M. J., and Tracey, A. S. (1990) Vanadates as phosphate analogs in biochemistry. In Vanadium in Biological System (Chasteen, N. D., Ed.) pp 63-79, Kluwer Academic Publishers, The Netherlands. 
(41) Cortizo, A. M., Salice, V. C., and Etcheverry, S. B. (1994) Vanadium compounds. Their action on alkaline phosphate activity. Biol. Trace Elem. Res. 41, 331-339.

(42) Crans, D. C. (1994) Aqueous chemistry of labile oxovanadate: relevance to biological studies. Comments Inorg. Chem. 16, 1-33.

(43) Chlopcikova, S., Psotova, J., and Miketova, P. (2001) Neonatal rat cardiomyocytes - A model for the study of morphological, biochemical and electrophysiological characteristics of the heart. Biomed. Pap. 145, 49-55.

(44) Martín-Romero, F. J., Santiago-Josefat, B., Correa-Bordes, J., Gutiérrez-Merino, C., and Fernandez-Salguero, P. (2000) Potassium-induced apoptosis in rat cerebellar granule cells involves cell-cycle blockade at the G1/S transition. J. Mol. Neurosci. 15, 155-165.

(45) Samhan-Arias, A. K., Martín-Romero, F. J., and Gutiérrez-Merino, C. (2004) Kaempferol blocks oxidative stress in cerebellar granule cells and reveals a key role for reactive oxygen species production at the plasma membrane in the commitment to apoptosis. Free Radical Biol. Med. 37, 48-71.

(46) Abu-Shakra, S., Alhalabi, M. S., Nachtman, F. C., Schemidt, R. A. and Brusilow, W. S. (1997) Anabolic steroids induce injury and apoptosis of differentiated skeletal muscle. J. Neurosci. Res. 47, 186197.

(47) Estabrook, R. W., Williamson, J. R., Frenkel, R., and Maitra, P. K. (1967) The fluorometric determination of mitochondrial adenine and pyridine nucleotides. Methods Enzymol. 10, 474-482.

(48) Guerini, D., García-Martín, E., Gerber, A., Volbracht, C., Leist, M. Gutiérrez-Merino, C., and Carafoli, E. (1999) The expression of plasma membrane $\mathrm{Ca}^{2+}$ pump isoforms in cerebellar granule neurons is modulated by $\mathrm{Ca}^{2+}$. J. Biol. Chem. 274, 1667-1676.

(49) García-Martín, E., Martín-Romero, F. J., and Gutiérrez-Merino, C. (1995) Intrasynaptosomal free $\mathrm{Mg}^{2+}$ concentration measured with the fluorescent indicator mag-fura-2: Modulation by $\mathrm{Na}^{+}$gradient and by extrasynaptosomal ATP. J. Neurochem. 65, 2757-2764.

(50) Thomas, A. P., and Delaville, F. (1991) The use of fluorescent indicators for measurements of cytosol-free calcium concentration in cell populations and single cells. In Cellular Calcium: A Practical Approach (McCormack, J. G., and Cobbold, P. H., Eds.) pp 1-54, Oxford University Press, Oxford.

(51) Greenlund, L. J., and Deckwerth, T. L., Jr. (1995) Superoxide dismutase delays neuronal apoptosis: A role for reactive oxygen species in programmed neuronal death. Neuron 14, 303-315.

(52) Keller, A., Mohamed, A., Drose, S., Brandt, U., Fleming, I., and Brandes, R. P. (2004) Analysis of dichlorodihydrofluorescein and dihydrocalcein as probes for the detection of intracellular reactive oxygen species. Free Radical Res. 38, 1257-1267.

(53) Budd, S. L., Castilho, R. F., and Nicholls, D. G. (1997) Mitochondrial membrane potential and hydroethidine-monitored superoxide generation in cultured cerebellar granule cells. FEBS Lett. 415, 21-24.

(54) Mathur, A., Hong, Y., Kemp, B. K., Barrientos, A. A., and Erusalimsky, J. D. (2000) Evaluation of fluorescent dyes for the detection of mitochondrial membrane potential changes in cultured cardiomyocytes. Cardiovasc. Res. 46, 126-138.

(55) Xu, M., Wang, Y., Ayub, A., and Ashraf, M. (2001) Mitochondrial $\mathrm{K}_{\mathrm{ATP}}$ channel activation reduces anoxic injury by restoring mitochondrial membrane potential. Am. J. Physiol. Heart Circ. Physiol. 281 H1295-H1303.

(56) Bradford, M. M. (1976) A rapid and sensitive method for the quantification of microgram quantities of protein utilizing the principle of protein-dye binding. Anal. Biochem. 72, 248-254.

(57) Aureliano, M., and Madeira, V. M. C. (1994) Interactions of vanadate oligomers with sarcoplasmic reticulum $\mathrm{Ca}^{2+}$-ATPase. Biochem. Biophys. Res. Commun. 205, 161-167.

(58) Aureliano, M., and Madeira, V. M. C. (1998) Energy transduction mechanisms as affected by vanadium(V) species: $\mathrm{Ca}^{2+}$-pumping in sarcoplasmic reticulum. In Vanadium in the Environment, Part 1: Chemistry and Biochemistry (Nriagu, J. O., Ed.) pp 333-357, John Wiley \& Sons, Inc., New York.

(59) Lascano, E. F., Gomez, R. M., and Berria, M. I. (1988) A controlled silver impregnation method to characterize cultured cardiomyocytes. Stain Technol. 63, 221-227.

(60) Takada, Y., Hashimoto, M., Kasahara, J., Aihara, K., and Fukunaga, K. (2004) Cytoprotective effect of sodium orthovanadate on ischaemia/ reperfusion - induced injury in the rat heart involves AkT activation and inhibition of fodrin breakdown and apoptosis. J. Pharmacol. Exp. Ther. 311, 1249-1255.

(61) Aon, M. A., Cortassa, S., Marban, E., and O'Rourke, B. (2003) Synchronized whole cell oscillations in mitochondrial metabolism triggered by a local release of reactive oxygen species in cardiac myocytes. J. Biol. Chem. 278, 44735-44744.
(62) Swift, L. M., and Sarvazyan, N. (2001) Localization of dichlorofluorescin in cardiac myocytes: Implications for assessment of oxidative stress. Am. J. Physiol. Heart Circ. Physiol. 278, H982-H990.

(63) Brennan, J. P., Southworth, R., Medina, R. A., Davidson, S. M., Duchen, M. R., and Shattock, M. J. (2006) Mitochondrial uncoupling, with low concentration FCCP, induces ROS-dependent cardioprotection independent of $\mathrm{K}_{\mathrm{ATP}}$ channel activation. Cardiovasc. Res. 72, 313-321.

(64) Soares, S. S., Gutiérrez-Merino, C., and Aureliano, M. (2007) Mitochondria as a target for decavanadate toxicity in Sparus aurata heart. Aquat. Toxicol. 83, 1-9.

(65) Chance, B., Sies, H., and Boveris, A. (1979) Hydroperoxide metabolism in mammalian organs. Physiol. Rev. 59, 527-605.

(66) Saotome, M., Katoh, H., Satoh, H., Nagasaka, S., Yoshihara, S., Terada, H., and Hayashi, H. (2005) Mitochondrial membrane potential modelates regulation of mitochondrial $\mathrm{Ca}^{2+}$ in rat ventricular myocytes. Am. J. Physiol. Heart Circ. Physiol. 288, H1820-H1828.

(67) Stern, A., Yin, X., Tsang, S. S., Davison, A., and Moon, J. (1993) Vanadium as a modulator of cellular regulatory cascades and oncogene expression. Biochem. Cell Biol. 71, 103-112.

(68) Colin, M., Madoulet, C., Baccard, N., Arsac, F., and Jardillier, J. C. (1994) Study of sodium orthovanadate as a reverser of multidrug resistance on lymphoblastic leukaemic CEM/VLB100 cells. Anticancer Res. 14, 2383-2388.

(69) Cruz, T. F., Morgan, A., and Min, W. (1995) In vitro and in vivo antineoplastic effects of orthovanadate. Mol. Cell. Biochem. 153, 161166.

(70) Caroni, P., and Carafoli, E. (1981) The $\mathrm{Ca}^{2+}$-pumping ATPase of heart sarcolemma. Characterization, calmodulin dependence, and partial purification. J. Biol. Chem. 256, 3263-3270.

(71) Sandirasegarane, L., and Gopalakrishnan, V. (1995) Vanadate increases cytosolic free calcium in rat aortic smooth muscle cells. Life Sci. 56, PL169-PL174.

(72) Braunwald, E. (1994) Vanadate increases cytosolic free calcium in rat aortic smooth muscle cells. Cardioscience 5, 139-144.

(73) Carmignani, M., Volpe, A. R., Masci, O., Boscolo, P., Di Giacomo, F., Grilli, A., Del Rosso, G., and Felaco, M. (1996) Vanadate as a factor of cardiovascular regulation by interactions with the catecholamine and nitric oxide systems. Biol. Trace Elem. Res. 51, 1-12.

(74) Nechay, B. R., Nanninga, L. B., and Nechay, P. S. (1986) Vanadate as a factor of cardiovascular regulation by interactions with the catecholamine and nitric oxide systems. Arch. Biochem. Biophys. 251, $128-138$

(75) Willenbucher, R. F., Xie, Y. N., and Eysselein, V. E., Jr. (1992) Mechanisms of camp-mediated relaxation of distal circular muscle in rabbit colon. Am. J. Physiol. 262, G159-G164.

(76) Mackenzie, L. H., Roderick, L., Berridge, M. J., Conway, S. T., and Bootman, M. D. (2004) The spatial pattern of atrial cardiomyocytes calcium signalling modulates contraction. J. Cell. Sci. 117, 6327-6337.

(77) Zorov, D. B., Juhaszova, M., and Sollott, S. J. (2006) Mitochondrial ROS-induced ROS release: An update and review. Biochim. Biophys. Acta 1757, 509-517.

(78) Boveris, A., and Cadenas, E. (1975) Mitochondrial production of superoxide anions and its relationship to the antimycin insensitive respiration. FEBS Lett. 54, 311-314.

(79) Lawrence, C. L., Billups, B., Rodrigo, G. C., and Standen, N. B. (2001) The $\mathrm{K}_{\mathrm{ATP}}$ channel opener diazoxide protects cardiac myocytes during metabolic inhibition without causing mitochondrial depolarization or flavoprotein oxidation. Br. J. Pharmacol. 134, 535-542.

(80) Ganote, C. E., and Armstrong, S. C. (2003) Effects of CCCP-induced mitochondrial uncoupling and cyclosporin A on cell volume, cell injury and preconditioning protection of isolated rabbit cardiomyocytes. $J$. Mol. Cell. Cardiol. 35, 749-759.

(81) Lim, D. C., Zuppinger, C., Guo, X., Kuster, G. M., Helmes, M., Eppenberger, H. M., Suter, T. M., Liao, R., and Sawyer, D. B. (2004) Antracyclines induce calpain-dependent titin proteolysis and necrosis in cardiomyocytes. J. Biol. Chem. 279, 8290-8299.

(82) Nechay, B. R. (1984) Mechanisms of action of vanadium. Annu. Rev. Pharmacol. Toxicol. 24, 501-524.

(83) O'Reilly, C. M., Fogarty, K. E., Drummond, R. M., Jr., and Walsh, J. V. (2004) Spontaneous mitochondrial depolarizations are independent of SR $\mathrm{Ca}^{2+}$ release. Am. J. Physiol. Cell Physiol. 286, 11391151 .

(84) Poindexter, B. J., Smith, J. R., Buja, L. M., and Bick, R. J. (2001) Calcium signalling mechanisms in dedifferentiated cardiac myocytes: Comparison with neonatal and adult cardiomyocytes. Cell Calcium 30, 373-382.

TX700204R 